\title{
Comparing Spanish L2 use of regional phonemes after study abroad in Spain and Mexico
}

Katherine R. Lindley

West Virginia University, kl0096@mix.wvu.edu

Follow this and additional works at: https://researchrepository.wvu.edu/etd

Part of the Modern Languages Commons, and the Spanish Linguistics Commons

\section{Recommended Citation}

Lindley, Katherine R., "Comparing Spanish L2 use of regional phonemes after study abroad in Spain and Mexico" (2021). Graduate Theses, Dissertations, and Problem Reports. 8089.

https://researchrepository.wvu.edu/etd/8089

This Thesis is protected by copyright and/or related rights. It has been brought to you by the The Research Repository @ WVU with permission from the rights-holder(s). You are free to use this Thesis in any way that is permitted by the copyright and related rights legislation that applies to your use. For other uses you must obtain permission from the rights-holder(s) directly, unless additional rights are indicated by a Creative Commons license in the record and/ or on the work itself. This Thesis has been accepted for inclusion in WVU Graduate Theses, Dissertations, and Problem Reports collection by an authorized administrator of The Research Repository @ WVU. For more information, please contact researchrepository@mail.wvu.edu. 
Comparing Spanish L2 use of regional phonemes after study abroad in Spain and Mexico

\author{
Katherine Lindley
}

Thesis submitted to the Eberly College of Arts and Sciences at West Virginia University in partial fulfillment of the requirements for the master degree of Linguistics in the Department of World Languages, Literatures, and Linguistics

Sergio Robles Puente, Ph.D, Co-chair

Nicole Tracy-Ventura, Ph.D, Co-chair

William Justin Morgan, Ph.D

Department of World Languages, Literatures, and Linguistics

\author{
Morgantown, West Virginia \\ 2021
}

Keywords: voiceless interdental fricative, study abroad, Spain, Mexico, sociolinguistic variation, phonological variation, second language acquisition

Copyright 2021 Katherine Lindley 


\begin{abstract}
Comparing Spanish L2 use of regional phonemes after study abroad in Spain and Mexico
\end{abstract}

Katherine Lindley

The present study analyzed the use of regional phonemes by native-English speakers before and after spending a year abroad in either Spain or Mexico. The variables selected were the interdental voiceless fricative $[\theta]$ and the uvular voiceless fricative $[\chi]$, along with their variations. Semi-structured oral interviews were used to elicit data before their sojourn and at the end of their stay. Results show that many participants used $[\theta]$ and $[\chi]$ more after spending a year in Spain and participants preferred [s] and [h] after spending a year in Mexico. Data on social networks were collected throughout the study for the Spain participants, though results show there was no correlation to the use of regional phonemes. Though many participants had strong social networks during their sojourn, their L2 identity was more of a "temporary sojourner," perhaps influenced by the ultimately multilingual study abroad experience. 


\section{Contents}

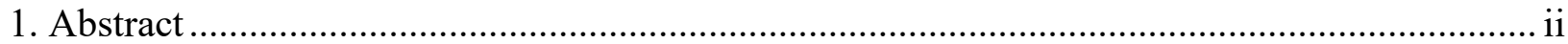

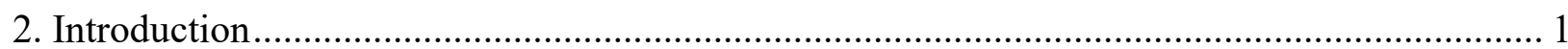

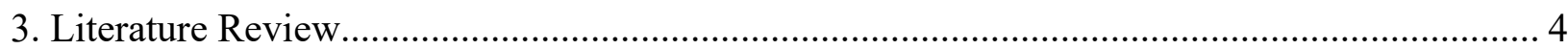

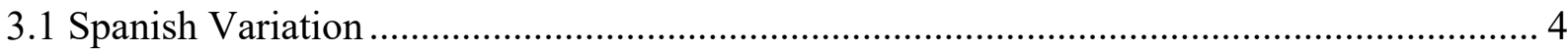

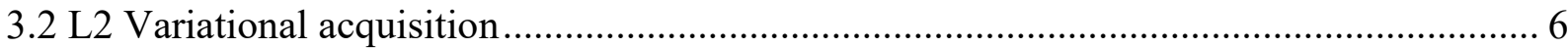

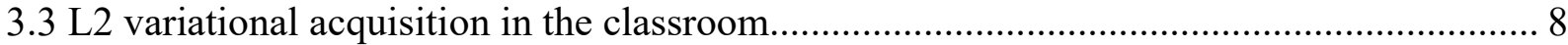

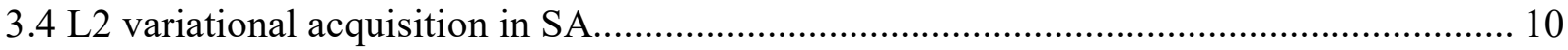

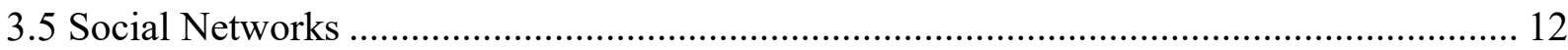

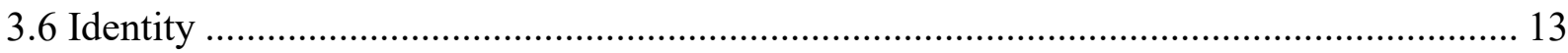

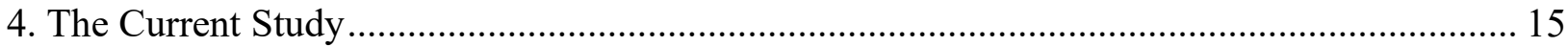

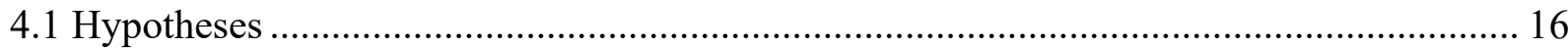

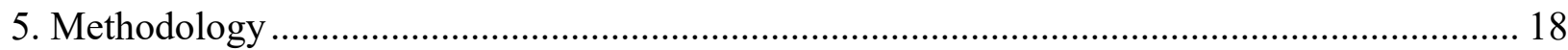

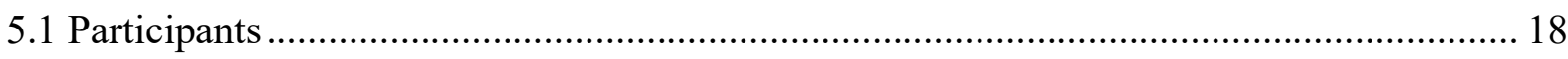

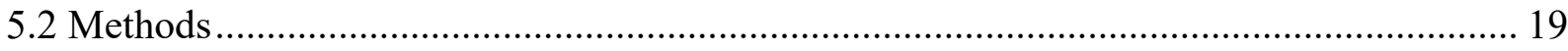

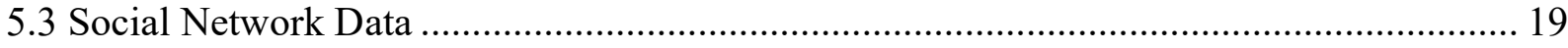

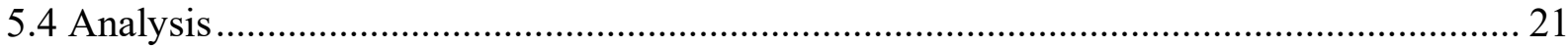

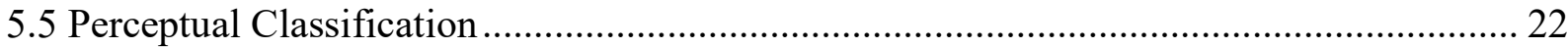

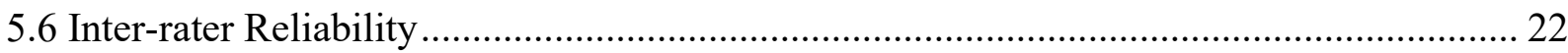

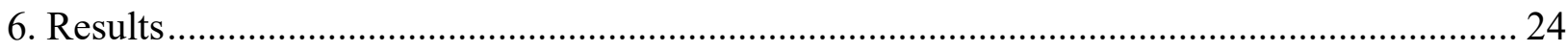

6.1 To what extent do participants who spent an academic year abroad use [ $\theta$ ] after their trip as

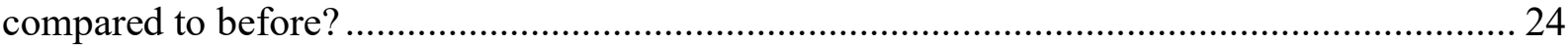

6.2 To what extent do participants use $[\mathrm{x}],[\mathrm{h}]$, and $[\chi]$ after their trip as compared to before, and how do the two groups differ in their use? .................................................................. 32

6.3 Are social networks and years of previous instruction related to L2 dialectal acquisition?36

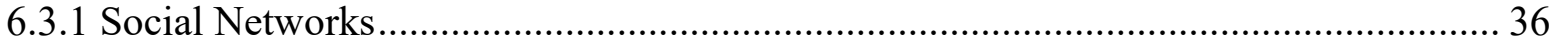

6.3.2 Years of Prior Instruction ................................................................................ 41

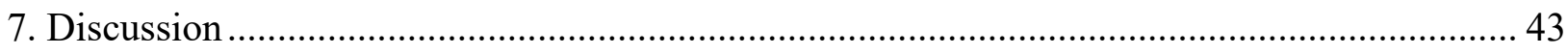

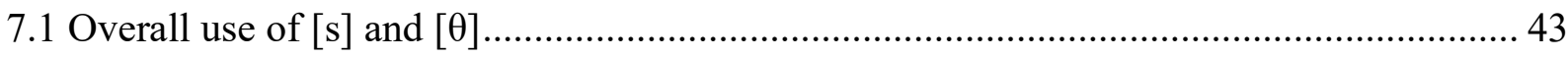

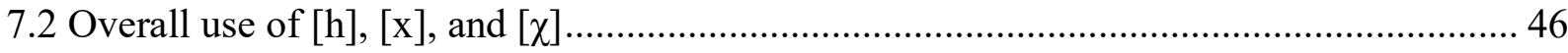

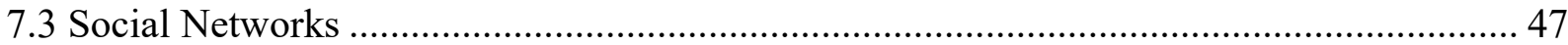

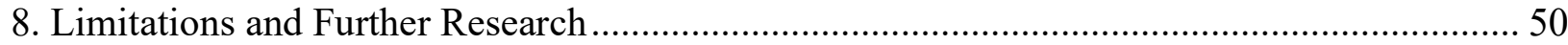

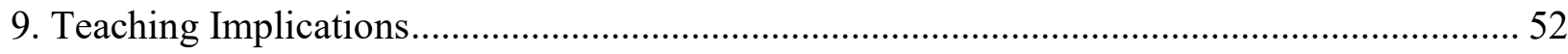




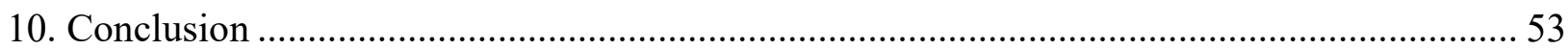

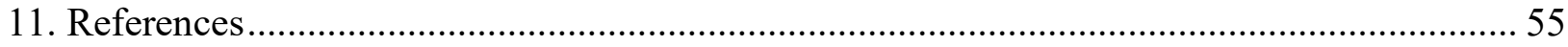

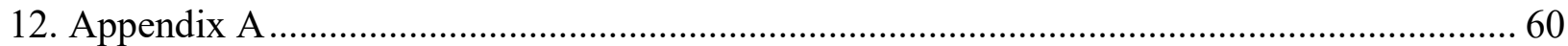

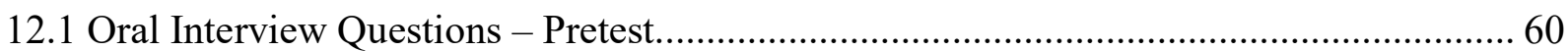

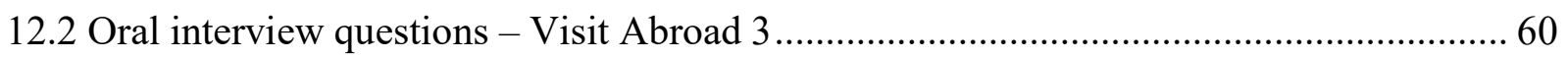




\section{Introduction}

Spanish is spoken as an official language in 20 countries, and Spanish speakers live in various countries all throughout the world. Each country has a unique dialect, and most countries have unique variations within their own borders. Even in the United States, where Spanish is the second most common language spoken, nearly every variation is represented (Lipski, 2008). This means that Spanish second language (L2) learners in the United States could interact with native speakers (NSs) of different dialects without ever having to leave the country. Despite this, many L2 classrooms do not provide instruction on phonological variational features, especially in lower-level courses. Studies show, however, that these variations are not only understood by L2 learners, but also acquired (Geeslin \& Gudmestad, 2008; Schoonmaker-Gates 2017). For L2 learners, understanding dialects may help with NS interaction.

The body of research regarding L2 acquisition of variational features emerged within the last decade and continues to grow (Diaz-Campos, 2004; Geeslin \& Gudmestad, 2008; George, 2014; Knouse, 2012; Pozzi, 2017; Ringer-Hilfinger, 2012; Schoonmaker-Gates, 2017). Many of these studies have investigated the potential relationship between study-abroad (SA) and L2 variational acquisition of phonological features, specifically comparing them to students in the classroom or at-home (AH) (Geeslin \& Gudmestad, 2008; Knouse, 2012; Schoonmaker-Gates, 2017). SA has long been considered ideal for linguistic gains in oral fluency and vocabulary, especially when compared to AH students (Freed \& Ferguson, 1995; Segalowitz \& Freed, 2004). If linguistic gains in oral fluency and vocabulary appear to be made quicker through SA experiences, L2 variational acquisition could also be made during those experiences, due to the high levels of NS contact. Using oral data, the present study seeks to expand upon this by 
analyzing L2 participants who studied abroad in two regions with differing phonological features: Spain and Mexico. By comparing two dialects and certain phonological features, the current study contributes to the growing body of research on L2 dialectal acquisition.

Recent studies, however, have not been able to account for why students rarely acquire variational features during SA despite improving in other linguistic areas (Knouse, 2012; Pozzi, 2017; Ringer-Hilfinger, 2012). While linguistic gains in oral fluency and vocabulary are necessary and important for L2 development, qualitative data suggests that even advanced L2 learners continue to struggle with comprehension of regional dialects during SA, which may affect production (Mitchell et al., 2017). Though proficiency is related to greater comprehension and fluency in the target language, the same does not seem to be true for acquisition of regional dialects. Lower proficiency learners are able to acquire these phonemes, though higher proficiency learners tend to do so more often (Geeslin \& Gudmestad, 2008 2010; George, 2014; Pozzi, 2017).

Other research suggests that individual differences play a more important role, specifically attitudes and perception of dialects, as well as L2 identity (Amoros-Negre, 2016; Ringer-Hilfinger, 2012; Schoonmaker-Gates, 2017). Dornyei's theory of the L2 ideal self(2009) is helpful in this aspect, as perhaps learners need to see themselves as confident L 2 users and part of the target culture in order to acquire these features. Evidence of this in reference to SA is shown in Mitchell et al. (2017) and further expanded upon in the Literature Review of the present study.

Overall, Spanish dialects are affecting L2 learners' experiences with the target language, primarily in comprehensibility and intelligibility (Mitchell et al., 2017; Muñoz \& Llanes, 2014; Munro \& Derwing, 1999; Schoonmaker-Gates, 2012). Some studies (Geeslin \& Gudmestad, 
2008; Schoonmaker-Gates, 2017) suggest that exposure is not sufficient for comprehension or acquisition, but explicit instruction is necessary. These findings show that L2 educators must implement specific strategies in order to improve comprehension of dialectal phonemes. To do so, a better understanding of L2 variational acquisition is needed, which the present study seeks to do.

One of the main goals of the present study is to expand on the question of whether SA is beneficial for acquisition of variational features. While most studies look at SA in short-term experiences, the present study is more longitudinal in that it looks at L2 learners who spent a year abroad. Not only does this allow for greater gains to be made in acquisition, but it also allows for growth in personal identity and interaction with NSs while abroad. This research is also unique in that it examines students in England who sojourned in Spain and others in Mexico. By comparing two different regions and all their phonological variational differences, more comprehensive conclusions can be made about L2 variational acquisition.

All data from the present study were collected as part of the Languages and Social Networks Abroad Project (LANGSNAP: Mitchell et al., 2017). L2 phonological development was not a focus of their research but the oral data and additional data on social networks makes it possible to investigate L2 phonological acquisition of variational features. This study draws on their data on identity, quality of social networks, and recorded oral interviews to examine L2 variational acquisition as a result of study abroad. 


\section{Literature Review}

\section{Spanish Variation}

Spanish variation refers to the vast differences that occur within the Spanish language, since no two Spanish speakers in the world speak the exact same Spanish. Diaz-Campos (2011) divides Spanish variation into "two fundamental categories: geographical variation, with little or no deviation within individual locations... and dialect-internal variation, where quantitative and qualitative phenomena vary among social strata, age- and gender-stratified groups, and other subdivisions linked with assertion of self-identity" (p. 72). This is to say that there is variation occurring within geographical locations, but also variation within those geographical locations as they relate to certain sociolinguistic factors, and each speaker may still have their own way of using language. The present study does not discount the necessity of dialect-internal variation, but its primary focus is on geographical variation.

Though this variation permeates every realm of language including phonology, syntax, and lexicon, this study is primarily focused on phonological variation. Previous studies have also primarily focused on phonological variation, specifically consonantal variation, which also seems to be the most productive area of research when it comes to variation (Diaz-Campos, 2011).

Spanish phonological variation has widely been studied as it relates to the realization of the voiceless alveolar fricative [s], particularly in word- and syllable-final positions, such as "coches" cars and "espejo" mirror. In this area of research, /s/ may be realized fully, aspirated as an $[\mathrm{h}]$, or deleted entirely, depending on the geographical region, which? occurs primarily in Latin America and certain areas of Spain, such as Andalusia and the Canary Islands (Hualde et 
al., 2012). While the present study is not focused on this specific variation, it is necessary to note its presence in studies on phonological variation.

A lesser, but still great portion of phonological variation studies focuses on the phenomenon of distinction. Distinction refers to the pronunciation of the graphemes "z," "ce," and "ci" as the voiceless interdental fricative $[\theta]$, and the production of " $\mathrm{s}$ " as $[\mathrm{s}]$. This primarily occurs in central and northern parts of Spain, while most of Latin America employs seseo, or in other words, pronounces "z," "ce," and "ci" as [s] in every context (Hualde et al., 2012). It is also interesting to note the use of ceceo, where "z," "ci," "ce," and "s", are realized as $[\theta]$, which occurs in the region of Andalusia and certain Central American dialects (Hualde et al., 2012). Examples of distinction, seseo, and ceceo are demonstrated below.

\begin{tabular}{|c|c|c|}
\hline Distinction & Seseo & Ceceo \\
\hline "casa" ['ka-sa] & "casa" ['ka-sa] & "casa" ['ka- $\theta \mathrm{a}]$ \\
\hline “caza” ['ka- $\theta a]$ & "caza" ['ka-sa] & "caza" ['ka- $\theta a]$ \\
\hline
\end{tabular}

Moving onto a different area of phonological variation, one which still includes fricatives, is the voiceless velar fricative [x]. Hualde et al. (2012) offers four possible variations: $[\mathrm{x}, \chi, \mathrm{h}, \mathrm{ç}](\mathrm{p} .97,2012)$. In Mexico, the glottal variation [h] is used, though there is evidence of the velar $[\mathrm{x}]$ realized in certain areas. In Spain, the velar $[\mathrm{x}]$ is much more common, with a large presence of the uvular $[\chi]$ particularly in northern and central regions. In Chilean varieties, the [x] sound is pronounced as [ç] when preceding /i/ and /e/ (Hualde et al., 2012). The current study focuses only on the first three $[\mathrm{x}, \chi, \mathrm{h}]$, as they are relevant to the regions analyzed. 
With Spain and Mexico being the two regions analyzed in the present study, the analysis concentrates on the use of $[\theta]$ and $[\mathrm{s}]$ and the different pronunciations of the voiceless velar fricative $[\mathrm{x}]$. The two phonemes used in the Mexican variety, $[\mathrm{s}]$ and $[\mathrm{h}]$, are in the phonemic

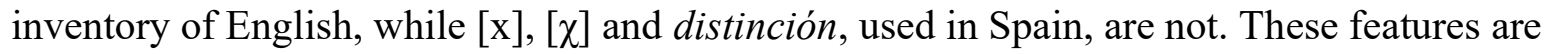
easily distinguishable between the two dialects, as demonstrated below.

\begin{tabular}{|c|c|}
\hline Spain & Mexico \\
\hline "hacer" [a-'Aer] & "hacer" [a-'ser] \\
\hline "gente" [' $\chi$ en-te $]$ & "gente" ["hen-te] \\
\hline
\end{tabular}

\section{L2 Variational Acquisition}

Despite the variety and breadth of research on phonological variation in Spanish, there have been few studies on this topic as it relates to L2 acquisition. For example, of the available research, most studies have focused on non-native production or perception of certain segmental features, particularly as the production relates to their first language (L1) (Geeslin, 2013).

L2 phonological acquisition, or pronunciation, is a contested area of research. It has long been considered one of the most difficult areas to acquire; though researchers have not been able to demonstrate the reasons behind this, many believe the difficulty is cognitive and not physical (Gilakjani et al., 2011). Shively (2008) identified five factors on whether or not L2 speakers would have accurate pronunciation: age, amount of formal instruction in Spanish, residence in a Spanish-speaking country, amount of out-of-class contact with Spanish (social networks), and motivation. These factors give context to whether or not L2 learners will have accurate 
pronunciation, rather than measuring their physical ability to achieve accuracy. The present study considers several of these factors as they relate to dialectal acquisition, particularly residence in a Spanish-speaking country and social networks.

Studies overwhelmingly affirm that phonology is an important aspect of L2 acquisition and that native-like competency in pronunciation is possible, even though it is quite difficult and not always a goal (George, 2014; Gilakjani et al., 2011; Munro \& Derwing, 1999). As it relates to L2 phonological acquisition of dialects, there are fewer studies, and their conclusions are much less concrete (George, 2014; Knouse, 2012; Ringer-Hilfinger, 2012).

Language and dialect are learned through use, as seen with babies acquiring whichever language and dialect is used in their environment. Babies adapt to the speech around them, and their output constantly adjusts to mirror the input that they have received (Nycz, 2013). In a 2013 study of L1 English Speakers, these skills of adaptation were shown to be used by more mature speakers as well; living in the United States and being immersed in the language affected certain verb properties of native Canadian English speakers (Nycz). In this study, participants showed variation within their L1, according to the dialect that they were immersed in. Could the same be true of L2 dialects?

Prior research suggests L2 learners can acquire certain phonological features when it comes to dialects (Diaz-Campos, 2004; Geeslin \& Gudmestad, 2008; Knouse, 2012; Nycz, 2013; Schoonmaker-Gates, 2017), but a 2011 study suggests they must be taught the rules and then taught how to implement them in natural conversation (Munson et al., 2011). With that in mind, many studies conclude that exposure or immersion alone to variational features such as the Spanish $/ \theta /$ does not seem sufficient for acquisition of such features; students need to be 
explicitly taught and exposed to certain dialects in order for acquisition to take place (Geeslin \& Gudmestad, 2008; Schoonmaker-Gates, 2017).

Miller and Schmitt (2010) suggested that Spanish-speaking children prefer their learned dialects as they become adults, specifically in dialects that have/s/-lenition. As L2 Spanish learners begin to become proficient in the language, being exposed to the same variety of Spanish in the classroom may affect them in the same way, causing them to acquire (and prefer) whichever variation is used by their instructors (Regan et al., 2009).

Since L2 phonological acquisition and dialectal acquisition are tied to exposure and perception, some studies have looked at these two factors when studying L2 phonological acquisition of dialects, though results are inconclusive (Pozzi, 2017; Ringer-Hilfinger, 2012). Some studies on this subject have analyzed the role of explicit instruction of dialectology, and while explicit instruction seems to benefit L2 dialectal acquisition, more research is needed (Geeslin \& Gudmestad, 2008; Knouse, 2012; Schoonmaker-Gates, 2017). When studying L2 phonological acquisition, it is necessary to consider the role of classroom instruction, as well as the context of SA.

\section{L2 variational acquisition in the classroom}

Students may acquire the style of language that they are exposed to and taught, so it is possible that the same is true with dialects and variations (Regan et al., 2009). In the United States, there is a strong preference for Latin American varieties in the L2 Spanish classroom (Hualde et al., 2012; Regan et al., 2009); therefore, it is unlikely that L2 learners will gain knowledge of the Castilian / $\theta$ / during their studies (Geeslin \& Gudmestad, 2008; Knouse, 2012; Schoonmaker-Gates, 2017). Since L2 learners are most likely to acquire the dialect that they are 
exposed to and taught, L2 learners may be acquiring more neutralized dialects, as suggested in Regan et al. (2009): "teachers will use more standard variants in class, leading students to believe that the standard variants are more favorable and will be more likely to use those and less likely to use other variants" (p. 127).

Researchers have suggested that introducing other variations as early as possible will aid students' understanding of the regional differences, and they will have the opportunity to acquire certain variations with increased exposure (Barron, 2005; Geeslin \& Gudmestad, 2008; Schoonmaker-Gates, 2017). For example, Schoonmaker-Gates (2017) analyzed students’ recognition of dialects and found that students' ability to recognize dialects was enhanced when coupled with explicit instruction, rather than relying on exposure alone. This study demonstrated that explicit instruction in the classroom can be beneficial for helping L2 learners better understand and potentially acquire phonological variation across different varieties of Spanish.

Results of many studies suggest that classroom instruction is beneficial to L2 dialectal acquisition, but this has been difficult to analyze because discussions of dialectology are typically absent from the typical language classroom. In their groundbreaking study, Geeslin \& Gudmestad analyzed 130 L2 Spanish participants in their use of two variational features: Castilian / $\theta /$ and /s/-weakening (2011). They found that of the 130 participants, only nine employed the use of $/ \theta$ /, with seven having studied abroad in various regions in mainland Spain, and two never having a SA experience (Geeslin \& Gudmestad, 2008). Of the nine participants who produced $[\theta]$, the authors note that for two lower-level proficiency speakers, "the learner who had been abroad only used [ $\theta$ ] once, whereas the one who had not been abroad demonstrated more regularized use" (2011, p. 147). This suggests that neither proficiency nor SA is necessary for acquisition of dialectal features. The participant who used this variant and had 
not studied abroad was shown to have contact with speakers who regularly employ this variant, thus suggesting that acquisition is possible without the SA experience as long as exposure was provided, either through the classroom or SNs.

On the contrary, Knouse in her analysis of 15 SA participants and 10 AH participants found that none of the $\mathrm{AH}$ participants produced the phoneme [ $\theta]$, even those with prior SA experience (2012). While only half of the SA participants realized [ $\theta]$ at least once and therefore were not consistent in their use of this variational feature, other analyses show that their L2 phonological production enhanced as a result of SA (Knouse, 2012). While classroom instruction can be beneficial, it appears that the context of learning, particularly SA, plays a significant role in dialectal acquisition.

\section{L2 variational acquisition in $\mathrm{SA}$}

SA has long been considered the best way to acquire a language, although research has shown that the strongest gains being made are typically related to lexis and oral fluency (Segalowitz \& Freed, 2004). Thus, SA seems ideal for L2 dialectal acquisition. The two previously mentioned studies (Geeslin \& Gudmestad, 2008; Knouse, 2012) indicate that SA is beneficial in this area; however, SA does not always predict whether students will acquire variational phonemes (Geeslin \& Gudmestad, 2008; Knouse, 2012). Students may acquire dialects more easily in SA, but SA is not a guarantee that they will acquire certain regional features.

Diaz-Campos (2004) compared AH and SA learners and found that they did not differ much regarding phonological acquisition, but L2 use outside of the classroom was a statistically significant factor. In terms of phonological acquisition, there were no "striking differences" 
between the SA and AH group in this study (p. 270, 2004). SA typically provides the context in which learners can interact with NSs outside of the classroom, but this study, using the Language Contact Profile $^{1}$ (LCP), suggests that SA is not required for this interaction nor acquisition of phonological features (Diaz-Campos, 2004). An L2 speaker could theoretically produce certain regional features without ever having been to that region.

Further supporting this, contact with NSs of varying dialects seems to be related to (non) acquisition of certain variational phonemes. Ringer-Hilfinger (2012), in a study of 28 L2 Spanish undergraduate learners, 15 who studied in Madrid and 13 in the classroom, collected data on dialectal acquisition at three points over a semester. This study found that very few employed the variational phoneme [ $\theta]$ and suggested that this is due to contact with NSs and instructors who did not use this phoneme (p. 441). Those L2 learners had already acquired the Latin American seseo dialects of their friends and professors, so despite having contact with distincion dialects while abroad, they may have been hesitant to acquire a new dialect (Ringer-Hilfinger, 2012). Contact with NSs during SA is important, but the type of contact and the variety spoken by NSs seem to be more important.

Very few studies have looked at the SA context regarding contact with NSs. Most studies compare SA to $\mathrm{AH}$ and find that NS contact is an important factor. It seems that SA is especially beneficial to variational acquisition when paired with significant L2 interaction. This relationship is examined in Pozzi's (2017) study of L2 learners in Buenos Aires, Argentina using the Social Network Strength Scale (SNSS) and speech data collected over several points. Pozzi alleges that the regional phonemes are so salient that strong social networks are irrelevant to acquisition in

\footnotetext{
${ }^{1}$ Tool for analysis that uses information such as age, L1, prior language experience, and current time spent using L2, both with other speakers and on their own via media.
} 
this context but that strong social networks did correlate positively with acquisition of certain regional lexical items. Having L2 learners of different proficiencies, this study suggested that proficiency is not necessary for L2 dialectal acquisition; however, it does conclude that proficiency impacts categorical use of regional phonemes and lexical items (Geeslin \& Gudmestad, 2008; George, 2014; Pozzi, 2017).

Ultimately, it seems that SA alone is not a reliable indicator of whether L2 learners will acquire variational features of the dialects in which they are immersed. Yet studies still affirm that SA is beneficial to L2 dialectal acquisition, so there must be other factors that, when coupled with SA, are related to acquisition. Some possible factors are explicit classroom instruction, exposure, awareness, proficiency, social networks (SNs), and other individual differences, such as identity and motivation. The present study considers the factors of SNs, identity, and proficiency. Previous research indicates that some or all these possible factors are valid, but many studies are inconclusive. Despite these inconclusive results, most studies do affirm that social networks and individual differences play a large role in L2 dialectal acquisition.

\section{Social Networks}

Contact with NSs is essential to L2 dialectal acquisition, and one of the ways many L2 learners achieve this contact is through SNs, having SNs with target-language speakers is typically more common during SA. In 1988, an ethnographic study of high school students demonstrated that for L1, SNs were a larger indicator of phonological variation than other factors such as socioeconomic class (Eckert, 1988). SNs are extremely important when it comes to the shaping of a L1, and many studies affirm that L2 dialectal acquisition relies on SNs as well (Eckert, 1988; Geeslin \& Gudmestad, 2008; George, 2014; Pozzi, 2017; Regan et al., 2009; Rubenfeld et al., 2006; Shively, 2008). 
In their book Mitchell et al. (2017) analyze the relationship between SNs and L2 acquisition during SA. They determine the quality of an SN by three factors: size, strength, and intensity. Qualitative and quantitative methods were used to investigate relationships between SN and L2 learning. The study showed that many LANGSNAP participants developed strong L2 relationships during SA and having strong SNs was used as a form of motivation to make linguistic gains (Mitchell et al., 2017, p. 245). A correlation was found between SNs and oral fluency as well as L2 confidence and a feeling of self-efficacy, which is further discussed below.

\section{Identity}

SNs are also vital to L2 dialectal acquisition as they contribute to the formation of L2 identity, as demonstrated in Rubenfeld et al. (2006). Using a self-questionnaire about L2 confidence, usage, media exposure, and community, this study suggested that there is a relationship between SNs and identity. In this study, it was suggested that learners who are confident in their L2 are more likely to build relationships around that L2, which then subsequently influences their L2 perceptions and actions. Thus, it has been suggested that SNs and identity ought to be analyzed together in order to obtain more comprehensive conclusions.

When it comes to L2 identity, many affirm that it is heavily constructed by social expectations (Baumeister, 1986; Block, 2007; Dörnyei \& Ushioda, 2009; Mitchell et al., 2017; Taylor, 2014). Following other LANGSNAP research (McManus et al., 2014; McManus et al., 2020; Mitchell et al., 2017), a definition of identity as it relates to social expectations is synthesized by Block (2007):

Socially constructed, self-conscious, ongoing narratives that individuals perform, interpret and project in dress, bodily movements, actions and language. Identity work occurs in the company of others - either face-to-face or in an electronically mediated 
mode - with whom to varying degrees individuals share beliefs, motives, values and practices. Identities are about negotiating new subject positions at the crossroads of the past, present and future. Individuals are shaped by their socio-histories but they also shape their socio-histories as life goes on. The entire process is conflictive as opposed to harmonious and individuals often feel ambivalent. There are unequal power relations to deal with, around the different capitals - economic, cultural and social - that both facilitate and constrain interactions with others in the different communities of practice with which individuals engage in their lifetimes. Finally, identities are related to different traditionally demographic categories such as ethnicity, race, nationality, migration, gender, social class and language (p. 27)

Yet, the public self is not the whole identity, as Mitchell et al. (2017) confirms the presence of the private self by quoting Baumeister (1986):

The public self is the self that is manifested in the presence of others, that is formed when other people attribute traits and qualities to the individual, and that is communicated to other people in the process of self-presentation. The private self is the way the person understands himself or herself and is the way the person really is (p. v).

Mitchell et al. (2017) then credits Taylor (2014) as forming an identity that consists of both selves, private and public. Yet, there is a difference between public and private self, which can be a motivator for change, similar to the L2 Motivational Self System (Dörnyei \& Ushioda, 2009; Taylor, 2014).

Dornyei's theory of the "L2 ideal self" includes the ideal self, ought self, goals to achieve the ideal self, and social expectations that form the ought self(2009). L2 learners have an idea of who they want to become (ideal self) and who they feel they ought to become (ought self), and 
are motivated to create harmony between the two selves (Dörnyei \& Ushioda, 2009). This motivation can be beneficial for L2 acquisition, and it is possible that the L2 ideal self can be related to L2 dialectal acquisition as well. Many studies explore the relationship between acquisition and identity (Dörnyei \& Ushioda, 2009; Mitchell et al., 2017), but few examine the relationship between identity and L2 dialectal acquisition. Those that do find that identifying with the target culture and positive experiences are beneficial to L2 dialectal acquisition (Knouse, 2012; Pozzi, 2017; Ringer-Hilfinger, 2012).

\section{The Current Study}

Though a relatively new subject, there are a handful of studies that seek to learn more about L2 dialectal acquisition (Diaz-Campos, 2004; Geeslin \& Gudmestad, 2008; George, 2014; Knouse, 2012; Pozzi, 2017; Ringer-Hilfinger, 2012; Schoonmaker-Gates, 2017). These studies have identified several factors such as classroom exposure and instruction, study abroad, proficiency, social networks, and identity that seem to influence L2 dialectal acquisition. Overall, more research is needed in order to learn more about L2 dialectal acquisition. The present study seeks to add to this growing body of research by answering the following questions:

1. To what extent do participants who spent an academic year abroad in either Spain or Mexico use $[\theta]$ and $[\mathrm{s}]$ after their trip as compared to before and how do the two groups differ in their use?

2. To what extent do participants use $[\mathrm{x}],[\mathrm{h}]$, and $[\chi]$ after their trip as compared to before, and how do the two groups differ in their use?

3. Are social networks and years of previous instruction related to L2 dialectal acquisition? 


\section{Hypotheses}

To what extent do participants who spent an academic year abroad in either Spain or Mexico

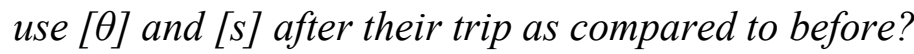

According to prior research (Geeslin \& Gudmestad, 2008; George, 2014; Knouse, 2012; Pozzi, 2017; Ringer-Hilfinger, 2012; Schoonmaker-Gates, 2017), most participants will not use $[\theta]$ in the pretest, and some participants who went to Spain are expected to increase in their use of the voiceless interdental fricative. Because of the various reasons that L2 learners acquire dialectal features, not all participants are expected to acquire this feature. It is also possible that many will be inconsistent and not categorical in the use of [ $\theta]$ after the trip abroad.

Those who went to Mexico are expected to not use [ $\theta]$ after SA, as that sound is not present in the variety of Spanish spoken in that region.

To what extent do participants use [x], [h], and [x] after their trip as compared to before, and how do the two groups differ in their use?

Since $[\mathrm{x}]$ and $[\chi]$ do not exist as phonemes in English and given the relationship between phonology of L1 and L2, many participants are expected to favor [h] prior to the trip abroad (Gilakjani et al., 2011; Munro \& Derwing, 1999; Shively, 2008). For those who went to Mexico, the preference for $[\mathrm{h}]$ is expected to stay, though $[\mathrm{x}]$ is present in certain areas, so there may be an increase in the use of that phoneme as well. For those who went to Spain, a shift is expected from $[\mathrm{h}]$ to $[\mathrm{x}]$ and an increase in the use of the uvular fricative $[\chi]$.

Are social networks and years of previous instruction related to L2 dialectal acquisition?

Since many studies affirm that L2 contact is largely related to L2 acquisition of phonemes (Diaz-Campos, 2004; Geeslin, 2013; Geeslin \& Gudmestad, 2008; Regan et al., 2009; 
Ringer-Hilfinger, 2012), it is expected that stronger SNs will be related to higher levels of acquisition of L2 dialectal features. The relationship between SNs and identity will also be important when looking at the present study, and identifying with the target language and culture will be related to variational acquisition (Block, 2007; Dörnyei \& Ushioda, 2009; Mitchell et al., 2017; Regan et al., 2009; Rubenfeld et al., 2006). Years of previous instruction, like with other studies (Geeslin \& Gudmestad, 2008; Knouse, 2012; Pozzi, 2017), will likely be irrelevant to levels of L2 dialectal acquisition. 


\section{Methodology}

\section{Participants}

This study consisted of 27 university students from England with English as their L1, though two participants were bilingual in Polish. ${ }^{2}$ As part of their program, they were required to spend one year abroad in a Spanish-speaking country. Of the 27 participants, 18 went to various regions in mainland Spain and 9 went to various regions in Mexico. There were three experience options during their time abroad: workplace intern, exchange student, or teaching assistant. Two students were workplace interns in Spain, nine students were exchange students in Spain, seven students were teaching assistants in Spain, and all nine students in Mexico were teaching assistants.

The group had 20 females and seven males. 15 of the females went to Spain, and five females went to Mexico. Only three males went to Spain and four males went to Mexico. They were all similar in age, ranging from 20-25, average age being 20.7 with a standard deviation of 1.4 years. All the students had spent at least two years learning Spanish, though there is a large variety of prior experience, with the mean age of first exposure being 15 years old (Mitchell et al., 2017). The range of experience learning Spanish is 2-14 years, with a median of six years of Spanish instruction. Every participant had experience in a Spanish-speaking country before going abroad, though these experiences were typically short-term, typically lasting for a week or less.

\footnotetext{
${ }^{2}$ The phonemic inventory of Polish includes the voiceless velar fricative [x] and the voiceless alveolar fricative [s], but not the interdental fricative [ $\theta]$. This L1 sound system did not seem to influence the L2 sound system differently than those with English L1.
} 


\section{Methods}

The LANGSNAP project includes six data collection points: a pretest, three visits incountry, and two posttests. During the collection points, the researchers administered a variety of tasks, and the data from three tasks are publicly available via the project website and Talkbank.org: a semi-structured oral interview, written argumentative essay, and a retelling of a picture-based narrative. The oral interviews at the pretest and third visit abroad were chosen as the two data collection points to be analyzed during this study. The oral interviews were chosen as they were the most comprehensive and natural of the two oral activities since this study is focused on phonological acquisition of dialectal features. The pretest data demonstrates their knowledge, skills, and language habits prior to sojourning in another country, and the data from the third visit abroad demonstrates their abilities as a result of their stay, just before their SA experience ends.

The interviews were semi-structured and lasted about 20 minutes. The questions were related to their daily activities, social lives, living situations, and challenges during their stay abroad (see Appendix A for the questions). In the pretest, these questions centered on plans, expectations, and how prior experiences may benefit them as they prepare. In the third visit abroad, the questions were reflective as the participants could speak about their lived experiences. The study consists of mixed methods, as qualitative data about regional accents and social networks were also derived from these interviews.

\section{Social Network Data}

As part of the LANGSNAP project, the researchers collected data on the participants' L2 use during their sojourn. Their social networks, specifically with the target language (TL), were 
analyzed according to size, strength, and intensity. To measure this, a questionnaire was designed and administered at each visit abroad collection point. To develop the Social Networks Questionnaire (SNQ), LANGSNAP researchers used the LCP (Freed et al., 2004) as a starting point (McManus et al., 2014). The development of the SNQ was heavily influenced by Milroy (1987) to measure quality of SNs, rather than the presence or absence This measured several contexts in which participants had the opportunity to build SNs, including work/school, organized free time (religious services, sports, etc.), general free time, home, and virtual social activities. Participants listed names of who they interacted with during these contexts, and answered the following questions based on those answers:

1. How often do you interact with this person?

2. What language(s) do you use when communicating with this person?

3. What is your relationship to this person?

4. How did you first meet? (McManus et al., 2014).

After answering for every context and listing names of their contacts, participants were asked to list the five people with whom they interact with the most in these contexts (McManus et al., 2014). Based on the questionnaire data, there were five areas in which the participants' social networks were analyzed, demonstrated below.

1. $2+$ people from work/university, TL/mixed interaction

2. $2+$ strong TL ties

3. At least 3 ties in mixed/TL interaction in free/organized time

4. 1+ TL/mixed tie in two different contexts (excluding homelife) 
5. At least 3 people from Top Five ${ }^{3}$ involve TL/mixed interaction (McManus et al., 2014; Mitchell et al., 2017)

For each statement that applied to a participant, they received one "point", so if they received a five on the questionnaire, that was an indicator of a strong L2 social network. If they received a one or a two, they likely had a weak L2 social network. In the current study, the SN data is compared to the use of regional phonemes in Spain, $[\theta]$ and $[\chi]$. This is consistent with prior research, in that native speaker interaction seems to be related to whether L2 learners will acquire dialectal phonemes (Geeslin \& Gudmestad, 2008; Knouse, 2012; Ringer-Hilfinger, 2012; Schoonmaker-Gates, 2017).

\section{Analysis}

The interviews were transcribed using the linguistic software CLAN. The transcriptions from CLAN were converted to a Word document, where only the transcripts of the participants' speech were present. The participants' speech was coded according to where certain phonemes are expected to be used according to their linguistic context. For example, the word hacer 'to do'

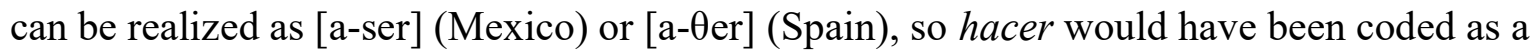
potential place for the phoneme $/ \theta /$ to be realized.

In accordance with the audio from the interviews, the transcriptions were then coded according to the phoneme that the participant used in each possible context. This was done for $[\theta],[\mathrm{s}],[\mathrm{h}],[\mathrm{x}]$, and $[\chi]$, each having their own unique code to indicate which sound was produced in each context. The differences between $[\theta]$ and $[\mathrm{s}]$ are relatively clear via perceptual

\footnotetext{
${ }^{3}$ Top Five refers to the five people in which they spend most of their time.
} 
analysis. The differences between $[\mathrm{h}],[\mathrm{x}]$, and $[\chi]$ varied slightly according to each participant, discussed further below.

\section{Perceptual Classification}

The differences between the three phonemes $[\mathrm{h}],[\mathrm{x}]$, and $[\chi]$, all produced near the back of the vocal tract, were characterized via perceptual analysis. When it came to analyzing dialectal acquisition, $[\mathrm{h}]$ was often compared to the use of $[\mathrm{x}]$ and $[\chi]$. That is to say, any increased use in $[\mathrm{x}]$ or $[\chi]$ in the Spain participants was regarded as dialectal acquisition, and any increase in $[\mathrm{h}]$ use for the Mexico participants was regarded as dialectal acquisition.

The features in the present study seemed to have two primary characteristics: friction and duration. Typically, the glottal phoneme [h] has little friction and a shorter duration, the velar phoneme $[\mathrm{x}]$ has more friction and an average duration, and the uvular phoneme $[\chi]$ has intense friction and a longer duration than the other phonemes. Nevertheless, since the levels of friction and duration showed wide intra- and inter-speaker variety and a clear phonetic differentiation was not always possible, the classification relied on a perceptual analysis. The author classified 1,696 tokens and compared that with other raters for increased validity.

\section{Inter-rater Reliability}

A sample of eight out of 54 audio and transcription files were analyzed by eight native speakers of Spanish, seven from Spain and one from Mexico. The seven speakers from Spain analyzed seven audio and transcript files from seven participants who went to Spain, and the speaker from Mexico analyzed an audio and transcript file from a participant who went to Mexico. The sample included a mix of pretest and posttest interviews, ones that were most 
problematic in perceptual classification. All eight of the native Spanish speakers have experience in phonology and participant information was not disclosed to any of them.

The native speakers listened to the interview audios and coded the transcriptions according to their perception of which phoneme was realized in contexts where certain phonemes would be realized. Out of eight interviews, there were 827 possible contexts of the analyzed phonemes $(/ \mathrm{s} /, / \theta /, / \mathrm{h} /, / \mathrm{x} /$, and $/ \chi /)$. Of the 827 possible contexts, initially 28 differences in perceptions of phonemes were found between their coding and those of the current study. After further analysis, only 18 were found to be erroneous. Those differences give a percentage error of about $2 \%$, though they were all subsequently edited according to the feedback of the native speakers. 


\section{Results}

To what extent do participants who spent an academic year abroad use [ $\theta]$ after their trip as compared to before?

\section{Table 1}

Use of [s] and [O] in pretest

\begin{tabular}{|c|c|c|c|c|c|}
\hline Group & Participant & $\begin{array}{l}{[\theta]} \\
\text { tokens }\end{array}$ & $\begin{array}{l}\mathrm{s}] \\
\text { tokens }\end{array}$ & $\begin{array}{l}\text { Total } \\
\text { tokens }\end{array}$ & $\begin{array}{l}\text { Percentage } \\
\text { of }[\theta] \text { use }\end{array}$ \\
\hline Spain & 150 & 33 & 4 & 75 & $44 \%$ \\
\hline \multirow{26}{*}{ Mexico } & 151 & 3 & 66 & 69 & $4 \%$ \\
\hline & 152 & 38 & 3 & 41 & $93 \%$ \\
\hline & 156 & 7 & 20 & 27 & $26 \%$ \\
\hline & 158 & 0 & 91 & 91 & $0 \%$ \\
\hline & 161 & 2 & 33 & 35 & $6 \%$ \\
\hline & 163 & 51 & 6 & 57 & $89 \%$ \\
\hline & 164 & 8 & 30 & 38 & $21 \%$ \\
\hline & 165 & 4 & 18 & 22 & $18 \%$ \\
\hline & 166 & 103 & 10 & 113 & $91 \%$ \\
\hline & 167 & 15 & 78 & 93 & $16 \%$ \\
\hline & 168 & 9 & 36 & 45 & $20 \%$ \\
\hline & 169 & 65 & 11 & 76 & $86 \%$ \\
\hline & 170 & 40 & 5 & 45 & $89 \%$ \\
\hline & 172 & 34 & 21 & 55 & $62 \%$ \\
\hline & 173 & 58 & 0 & 58 & $100 \%$ \\
\hline & 174 & 3 & 30 & 33 & $9 \%$ \\
\hline & 180 & 0 & 52 & 52 & $0 \%$ \\
\hline & 155 & 56 & 8 & 64 & $88 \%$ \\
\hline & 157 & 24 & 5 & 29 & $83 \%$ \\
\hline & 160 & 1 & 59 & 60 & $2 \%$ \\
\hline & 162 & 0 & 52 & 52 & $0 \%$ \\
\hline & 171 & 0 & 58 & 58 & $0 \%$ \\
\hline & 175 & 30 & 10 & 40 & $75 \%$ \\
\hline & 177 & 76 & 5 & 81 & $94 \%$ \\
\hline & 178 & 7 & 17 & 24 & $29 \%$ \\
\hline & 179 & 11 & 22 & 33 & $33 \%$ \\
\hline
\end{tabular}


Table 1 shows the use of $[\mathrm{s}]$ and $[\theta]$ during the pretest. There were only four participants (158, $180,162,171)$ who did not produce a single instance of $[\theta]$ during the pretest. Participants 151 , 161,174 , and 160 used $[\theta]$ in less than $10 \%$ of possible contexts. Though there were some participants who clearly favored [ $\theta$, only one (173) did not produce a single instance of [s] in the possible contexts. The pretest data clearly shows evidence of exposure to [ $\theta]$ prior to the study. Many participants had previously traveled briefly to Spain, which could give them exposure to that sound, as well as the possibility of L2 instructors employing this variant. 


\begin{tabular}{|c|c|c|c|c|c|}
\hline \multicolumn{6}{|c|}{ 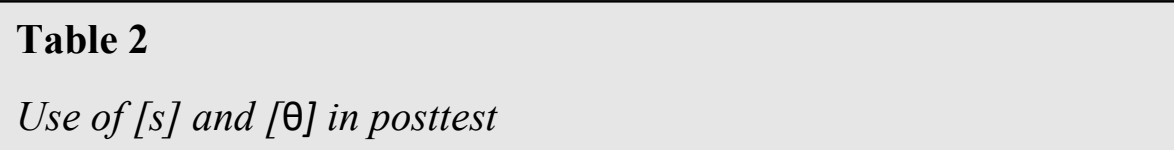 } \\
\hline Group & Participant & $\begin{array}{l}{[\theta]} \\
\text { tokens }\end{array}$ & $\begin{array}{l}{[\mathrm{s}]} \\
\text { tokens }\end{array}$ & total & {$[\theta] \%$} \\
\hline Spain & 150 & 104 & 9 & 113 & $92 \%$ \\
\hline \multirow{26}{*}{ Mexico } & 151 & 10 & 62 & 72 & $14 \%$ \\
\hline & 152 & 35 & 1 & 36 & $97 \%$ \\
\hline & 156 & 89 & 5 & 94 & $95 \%$ \\
\hline & 158 & 0 & 110 & 110 & $0 \%$ \\
\hline & 161 & 48 & 3 & 51 & $94 \%$ \\
\hline & 163 & 71 & 2 & 73 & $97 \%$ \\
\hline & 164 & 6 & 44 & 50 & $12 \%$ \\
\hline & 165 & 15 & 64 & 79 & $19 \%$ \\
\hline & 166 & 101 & 7 & 108 & $94 \%$ \\
\hline & 167 & 51 & 65 & 116 & $44 \%$ \\
\hline & 168 & 63 & 6 & 69 & $91 \%$ \\
\hline & 169 & 108 & 6 & 114 & $95 \%$ \\
\hline & 170 & 61 & 0 & 61 & $100 \%$ \\
\hline & 172 & 102 & 10 & 112 & $91 \%$ \\
\hline & 173 & 57 & 5 & 62 & $92 \%$ \\
\hline & 174 & 2 & 43 & 45 & $4 \%$ \\
\hline & 180 & 95 & 42 & 137 & $69 \%$ \\
\hline & 155 & 1 & 80 & 81 & $1 \%$ \\
\hline & 157 & 0 & 43 & 43 & $0 \%$ \\
\hline & 160 & 0 & 46 & 46 & $0 \%$ \\
\hline & 162 & 0 & 39 & 39 & $0 \%$ \\
\hline & 171 & 0 & 38 & 38 & $0 \%$ \\
\hline & 175 & 0 & 70 & 70 & $0 \%$ \\
\hline & 177 & 0 & 56 & 56 & $0 \%$ \\
\hline & 178 & 0 & 58 & 58 & $0 \%$ \\
\hline & 179 & 0 & 85 & 85 & $0 \%$ \\
\hline
\end{tabular}

Table 2 demonstrates the use of [ $\theta]$ during the third visit abroad, the posttest, after having spent a year in either Spain or Mexico. Of the participants who went to Spain, there is only one participant (158) who did not use [ $\theta$ ] in any of the possible contexts. Only one participant (170) 
used $[\theta]$ in $100 \%$ of contexts, though $11(150,152,156,161,163,166,168,169,170,172,173)$ participants used $[\theta]$ in at least $90 \%$ of contexts. Of the participants who went to Mexico, there was only one single use of [ $\theta]$ in all the posttests. Participant 155 used [ $\theta]$ about $1 \%$ of the time (one instance), and all other participants $(157,160,162,171,175,177,178,179)$ used $[\mathrm{s}] 100 \%$ of the time.

\section{Figure 1. Use of $[\theta]$ by participants in Spain \\ Pretest Visit Abroad 3}

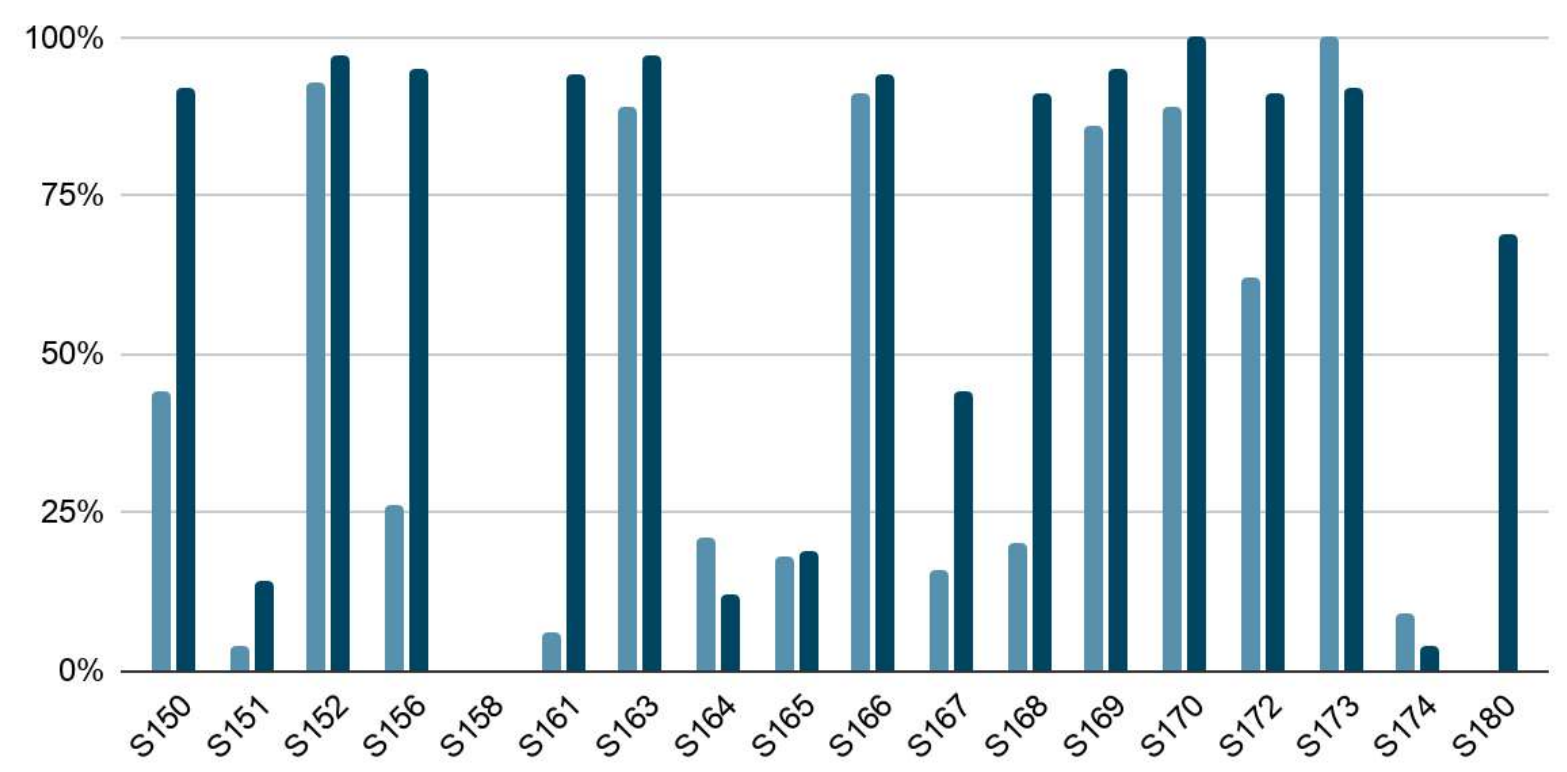

Figure 1 focuses on the $[\theta]$ results in the participants who went to Spain. Just as previously mentioned, there is far more usage of this regional feature in this data than in previous research. All participants except participant 158 demonstrated use of [ $\theta]$ in the posttest. Of the two participants (158 and 180) who did not use [ $\theta]$ at all in the pretest, only participant 180 showed use in the posttest. 11 out of 18 participants utilized $[\theta]$ in over $75 \%$ of contexts during 
the posttest, and 12 used it in over $50 \%$ of contexts. The mean percentage use of [ $\theta]$ in the pretest was $43 \%$ (median $23.5 \%$ ); the mean in the posttest was $67 \%$ (median $91.5 \%$ ).

\section{Figure 2. Use of $[\theta]$ by participants in Mexico}

Pretest $\square$ Visit Abroad 3

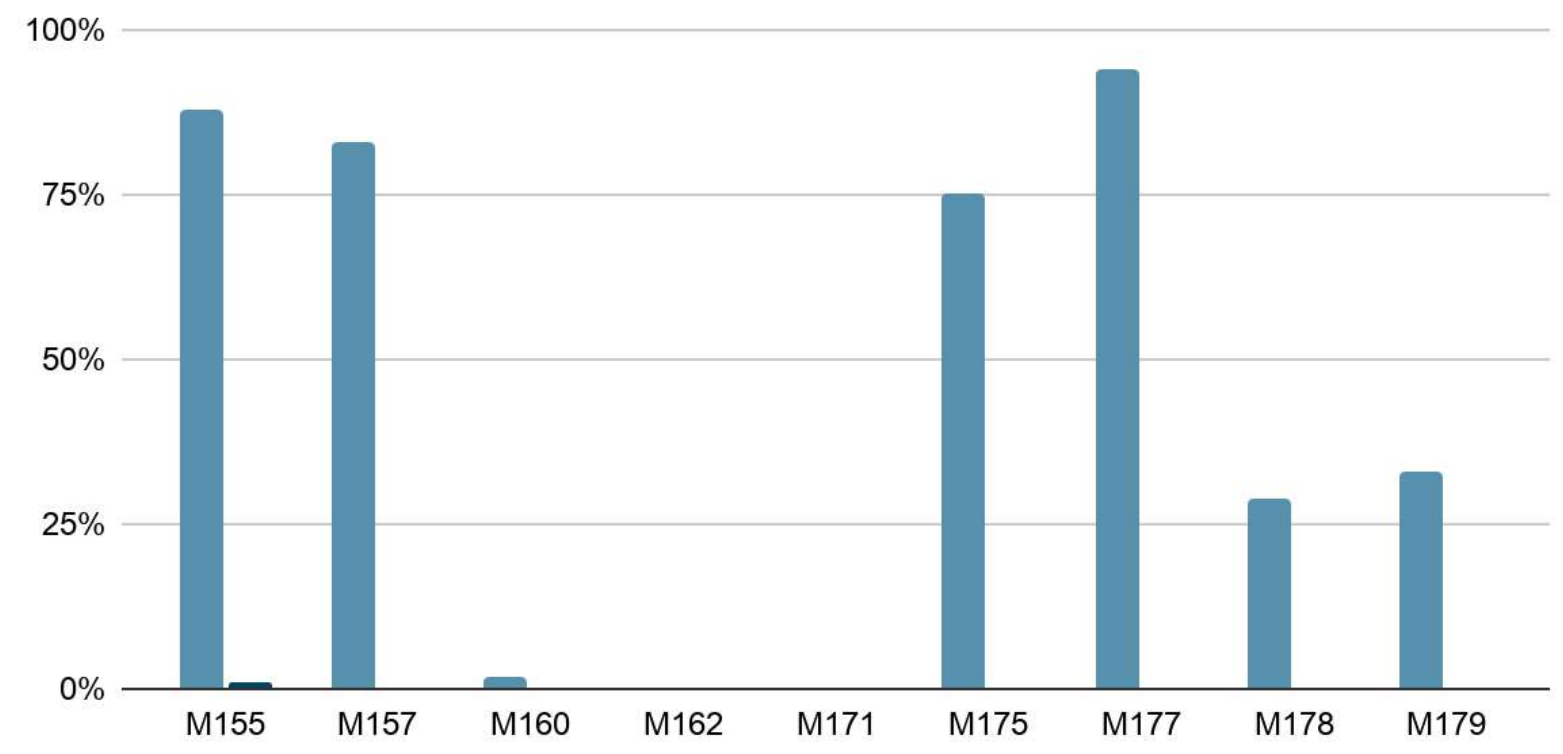

Figure 2 demonstrates the usage of $[\theta]$ in the participants who went to Mexico, both in the pretest and the posttest. All the participants who went to Mexico $(155,157,160,162,171$, $175,177,178,179)$ drastically changed in their use of $[\theta]$, as all except two $(162,171)$ used $[\theta]$ prior to their trip and all except one (155) did not use [ $\theta]$ at any point in the posttest. It is worth noting that participant 155 used $[\theta]$ in only one context out of the 81 possible contexts.

Because there was so much prevalence of the regional feature both in the pretest and posttest, it is important to look at the percentage of change in its use, as represented in Figures 3 and 4. The difference in change is clearly noted between the participants who went to Spain and the participants who went to Mexico. 


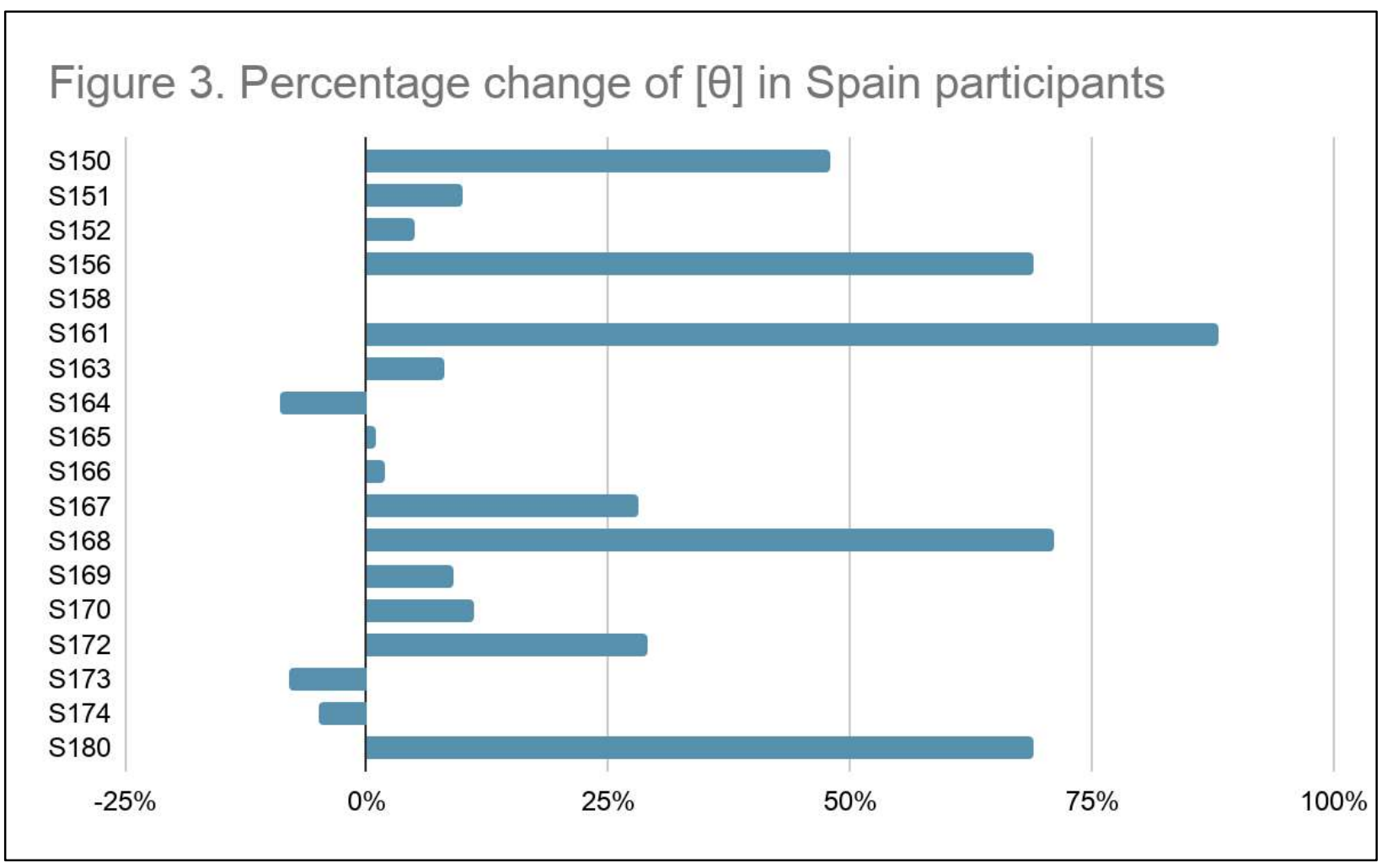

Figure 3 isolates the percentage of change in use of $[\theta]$ in the participants who studied abroad in Spain. The mean percentage of change is $23.7 \%$, median $9.5 \%$. There were four participants $(158,164,173,174)$ who did not have a positive change, with three of those using $[\theta]$ less in the posttest than the pretest. Participant 158 did not use [ $\theta]$ in the pretest nor the posttest, so it can be concluded that this regional feature was never acquired by this participant. Participant 173 used $[\theta]$ in $100 \%$ of contexts in the pretest, and $92 \%$ of contexts in the posttest, an $8 \%$ drop. These are both extremely high levels of use for this regional feature, so it is most likely that this participant did not actually change their use of the feature as the data appears to show. The same may be true for participants 164 and 174, who both had small levels of change ( $9 \%$ and $5 \%$ respectively). It is possible that the participants did not change in their use of [ $\theta]$. Participants $152,163,165,166$, and 169 all had a small percentage of positive change less than 
the median $9.5 \%$, so it is unclear whether their use changed or simply varied as a result of two different tests. That leaves nine participants $(150,151,156,161,167,168,170,172$, and 180) who had a positive change of $9.5 \%$ or higher.

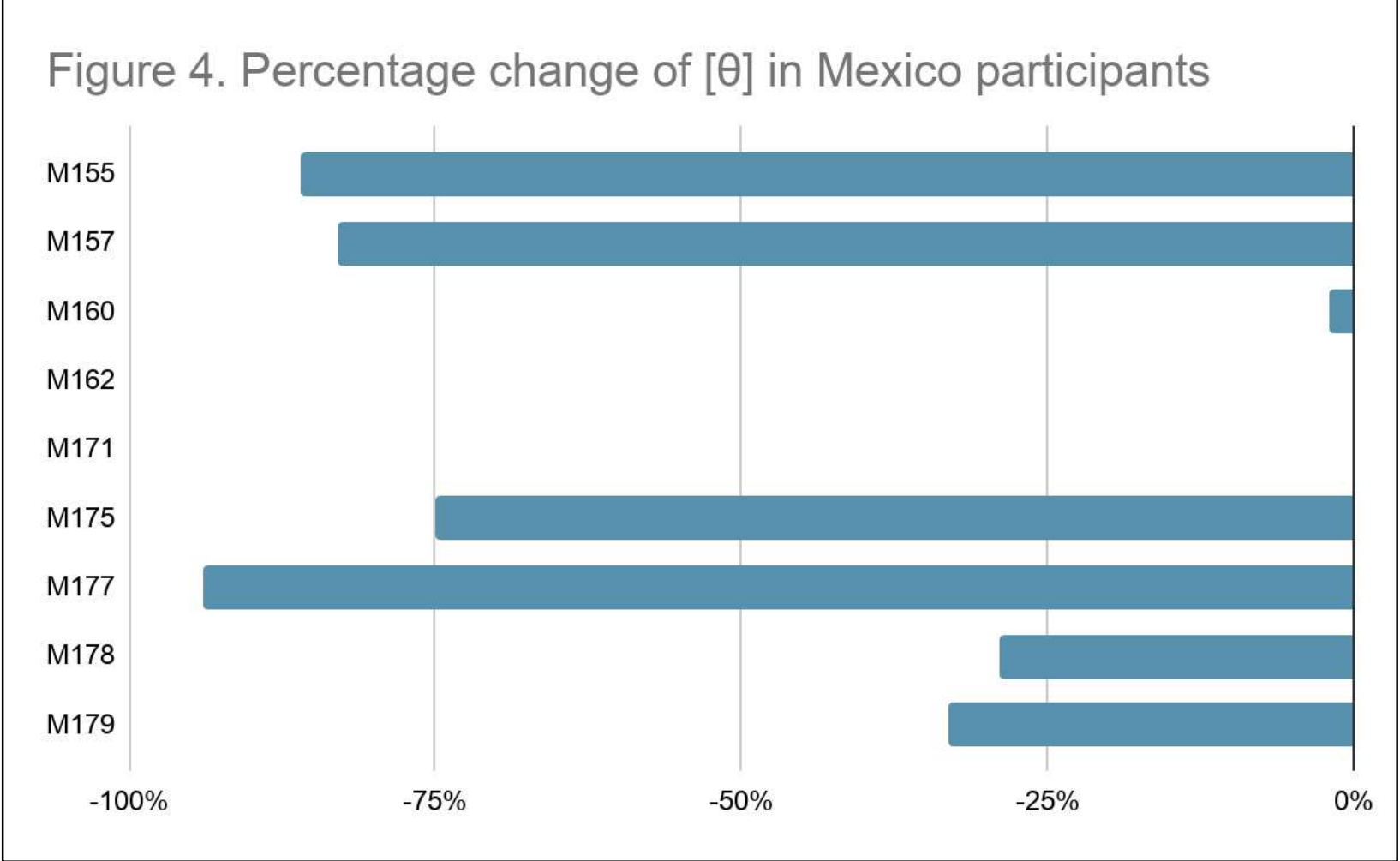

Figure 4 isolates the participants who went to Mexico and their use of [ $\theta]$. Because this feature is not used in Mexico, it is expected that participants would not increase in their use of it. Unlike previous studies, these participants showed use of the regional feature during the pretest, so despite going to a region where this feature is not used, its use can still be measured. As previously mentioned, every participant except two $(162,171)$ used $[\theta]$ at least once in the pretest, and every participant stopped using it during the posttest. This study was not originally focused on the acquisition of [s], however the data shows that participants have increased in their usage of this phoneme that is used in the region where they were studying. 
While there is a wide variety in usage of $[\theta]$ for all participants, it is much higher than that of previous studies (Geeslin \& Gudmestad, 2008; Knouse, 2012; Ringer-Hilfinger, 2012; Schoonmaker-Gates, 2017), which typically demonstrate little use of [ $\theta$ ] in Spanish L2 speakers, both in pretests and posttests. Participant 173 used [ $\theta]$ in every possible context in the pretest $(n=58)$, while participant 170 used $[\theta]$ in every possible context in the posttest $(n=61)$. In the pretest, the mean percentage of [ $\theta]$ use was $43.6 \%$ (43\% for Spain participants). For the Spain participants, the mean use of [ $\theta]$ was $66.7 \%$, with a median of $91.5 \%$ in the posttest. 
To what extent do participants use $[x],[h]$, and $[\chi]$ after their trip as compared to before, and how do the two groups differ in their use?

Table 3

[x] variant results in pretest

\begin{tabular}{|c|c|c|c|c|c|c|c|c|}
\hline Group & Part. & {$[\mathrm{h}]$} & {$[\mathrm{x}]$} & {$[\chi]$} & total & {$[\mathrm{h}] \%$} & {$[\mathrm{x}] \%$} & {$[\chi] \%$} \\
\hline \multirow[t]{18}{*}{ Spain } & 150 & 39 & 19 & 0 & 58 & 67.2 & 32.8 & 0 \\
\hline & 151 & 27 & 0 & 0 & 27 & 100 & 0 & 0 \\
\hline & 152 & 10 & 19 & 0 & 29 & 34.5 & 65.5 & 0 \\
\hline & 156 & 15 & 3 & 0 & 18 & 83.3 & 16.7 & 0 \\
\hline & 158 & 53 & 0 & 0 & 53 & 100 & 0 & 0 \\
\hline & 161 & 24 & 0 & 0 & 24 & 100 & 0 & 0 \\
\hline & 163 & 5 & 12 & 0 & 17 & 29.4 & 70.6 & 0 \\
\hline & 164 & 16 & 7 & 0 & 23 & 69.6 & 30.4 & 0 \\
\hline & 165 & 31 & 1 & 0 & 32 & 96.9 & 3.1 & 0 \\
\hline & 166 & 26 & 5 & 0 & 31 & 83.9 & 16.1 & 0 \\
\hline & 167 & 19 & 11 & 4 & 34 & 55.9 & 32.4 & 11.8 \\
\hline & 168 & 38 & 0 & 0 & 38 & 100 & 0 & 0 \\
\hline & 169 & 21 & 10 & 0 & 31 & 67.7 & 32.3 & 0 \\
\hline & 170 & 20 & 0 & 0 & 20 & 100 & 0 & 0 \\
\hline & 172 & 16 & 0 & 0 & 16 & 100 & 0 & 0 \\
\hline & 173 & 15 & 0 & 0 & 15 & 100 & 0 & 0 \\
\hline & 174 & 21 & 0 & 0 & 21 & 100 & 0 & 0 \\
\hline & 180 & 44 & 6 & 0 & 50 & 88 & 12 & 0 \\
\hline \multirow[t]{9}{*}{ Mexico } & 155 & 15 & 17 & 0 & 32 & 46.9 & 53.1 & 0 \\
\hline & 157 & 1 & 14 & 0 & 15 & 6.7 & 93.3 & 0 \\
\hline & 160 & 28 & 5 & 0 & 33 & 84.8 & 15.1 & 0 \\
\hline & 162 & 19 & 11 & 0 & 30 & 63.3 & 36.7 & 0 \\
\hline & 171 & 30 & 3 & 0 & 33 & 90.9 & 9.1 & 0 \\
\hline & 175 & 21 & 5 & 3 & 29 & 72.4 & 17.2 & 10.3 \\
\hline & 177 & 27 & 29 & 1 & 57 & 47.4 & 50.9 & 1.8 \\
\hline & 178 & 25 & 8 & 0 & 33 & 75.8 & 24.2 & 0 \\
\hline & 179 & 23 & 0 & 0 & 23 & 100 & 0 & 0 \\
\hline
\end{tabular}


Table 3 demonstrates the variation of the velar fricative used by the participants during the pretest. Three participants $(167,175,177)$ used the uvular fricative $[\chi]$ at least once, though the highest percentage was only $11.76 \%$ of the time. While there was less use of this variant than $[\theta]$, this still indicates prior exposure via travel or in the classroom. Many speakers preferred the glottal fricative $[\mathrm{h}]$ during the pretest, as nine participants $(151,158,161,168,170,172,173$, $174,179)$ used $[\mathrm{h}]$ in $100 \%$ of possible contexts. Only five participants did not prefer [h], and those five $(152,163,155,157,177)$ all preferred the velar fricative $[\mathrm{x}]$. 


\begin{tabular}{|c|c|c|c|c|c|c|c|c|}
\hline \multicolumn{9}{|c|}{$\begin{array}{l}\text { Table } 4 \\
{[x] \text { variant results in posttest }}\end{array}$} \\
\hline Group & Part. & {$[\mathrm{h}]$} & {$[\mathrm{x}]$} & {$[\chi]$} & total & {$[\mathrm{h}] \%$} & {$[\mathrm{x}] \%$} & {$[\chi] \%$} \\
\hline Spain & 150 & 10 & 19 & 31 & 60 & 16.7 & 31.7 & 51.7 \\
\hline \multirow{26}{*}{ Mexico } & 151 & 24 & 1 & 1 & 26 & 92.3 & 3.8 & 3.8 \\
\hline & 152 & 3 & 17 & 6 & 26 & 11.5 & 65.4 & 23.1 \\
\hline & 156 & 16 & 20 & 1 & 37 & 43.2 & 54.1 & 2.7 \\
\hline & 158 & 40 & 13 & 0 & 53 & 75.5 & 24.5 & 0 \\
\hline & 161 & 20 & 7 & 0 & 27 & 74.1 & 25.9 & 0 \\
\hline & 163 & 6 & 12 & 5 & 23 & 26.1 & 52.2 & 21.7 \\
\hline & 164 & 9 & 10 & 1 & 20 & 45 & 50 & 5 \\
\hline & 165 & 21 & 8 & 1 & 30 & 70 & 26.7 & 3.3 \\
\hline & 166 & 19 & 9 & 1 & 29 & 65.5 & 31 & 3.4 \\
\hline & 167 & 14 & 16 & 28 & 58 & 24.1 & 27.6 & 48.3 \\
\hline & 168 & 26 & 3 & 1 & 30 & 86.7 & 10 & 3.3 \\
\hline & 169 & 22 & 16 & 1 & 39 & 56.4 & 41 & 2.6 \\
\hline & 170 & 4 & 7 & 3 & 14 & 28.6 & 50 & 21.4 \\
\hline & 172 & 27 & 1 & 0 & 28 & 96.4 & 3.6 & 0 \\
\hline & 173 & 52 & 1 & 0 & 53 & 98.1 & 1.9 & 0 \\
\hline & 174 & 27 & 3 & 0 & 30 & 90 & 10 & 0 \\
\hline & 180 & 29 & 14 & 1 & 44 & 65.9 & 31.8 & 2.3 \\
\hline & 155 & 24 & 12 & 0 & 36 & 66.7 & 33.3 & 0 \\
\hline & 157 & 7 & 8 & 0 & 15 & 46.7 & 53.3 & 0 \\
\hline & 160 & 20 & 1 & 0 & 21 & 95.2 & 4.8 & 0 \\
\hline & 162 & 28 & 6 & 0 & 34 & 82.4 & 17.6 & 0 \\
\hline & 171 & 21 & 1 & 0 & 22 & 95.5 & 4.5 & 0 \\
\hline & 175 & 32 & 3 & 0 & 35 & 91.4 & 8.6 & 0 \\
\hline & 177 & 22 & 5 & 0 & 27 & 81.58 & 18.5 & 0 \\
\hline & 178 & 31 & 5 & 0 & 36 & 86.1 & 13.9 & 0 \\
\hline & 179 & 18 & 6 & 0 & 24 & 75 & 25 & 0 \\
\hline
\end{tabular}

After the year abroad, the results of the variational use of $[\mathrm{x}]$ varied as well, as shown in Figure 4. Of the participants who went to Spain, only five $(158,161,172,173,174)$ demonstrated no use of the uvular fricative $[\chi]$. Of these five, $[\mathrm{h}]$ was used in $100 \%$ of contexts during the pretest. While the posttest results show a clear preference for [h], all five of these 
participants were able to incorporate the velar fricative $[\mathrm{x}]$ into their speech during their time in Spain. Only two participants (150 and 167) favored the uvular fricative $[\chi]$ and five participants $(152,156,163,164,170)$ showed a preference for the velar fricative $[\mathrm{x}]$. As expected, there was no use of $[\chi]$ in the participants who went to Mexico, and only one participant (157) preferred the velar $[\mathrm{x}]$. Though all the participants utilized $[\mathrm{x}]$ during the posttest, all but one preferred the glottal fricative $[\mathrm{h}]$.

\section{Figure 5. [X]\% use in Spain participants \\ Pretest $\square$ Posttest}

$75.00 \%$

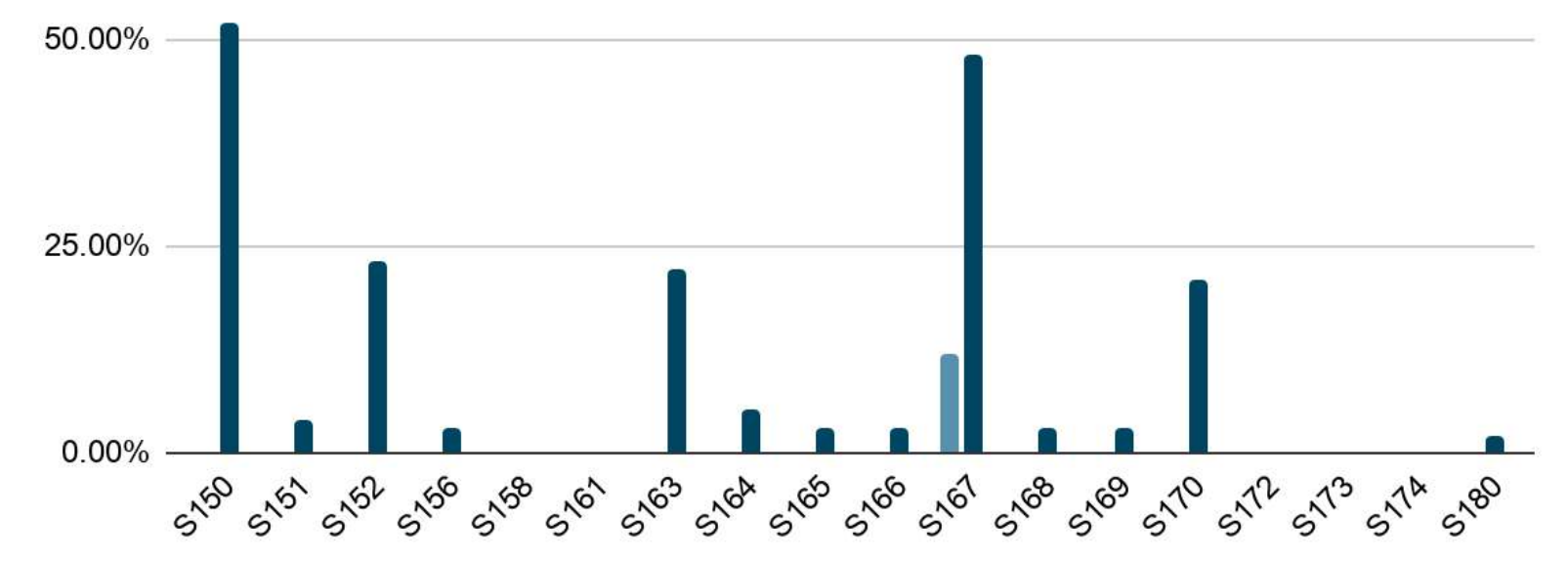

The use of $[\chi]$ by participants in Spain in the pretest and posttest is demonstrated in Figure 5. Most participants $(n=13)$ acquired this regional phoneme during their time abroad, even though all except one (167) did not use it during the pretest. In the posttest, the mean use of $[\chi]$ was $10.7 \%$, with the median being only $3 \%$. 


\section{Figure 6. [X] \% change in Spain participants}

$$
60 \%
$$

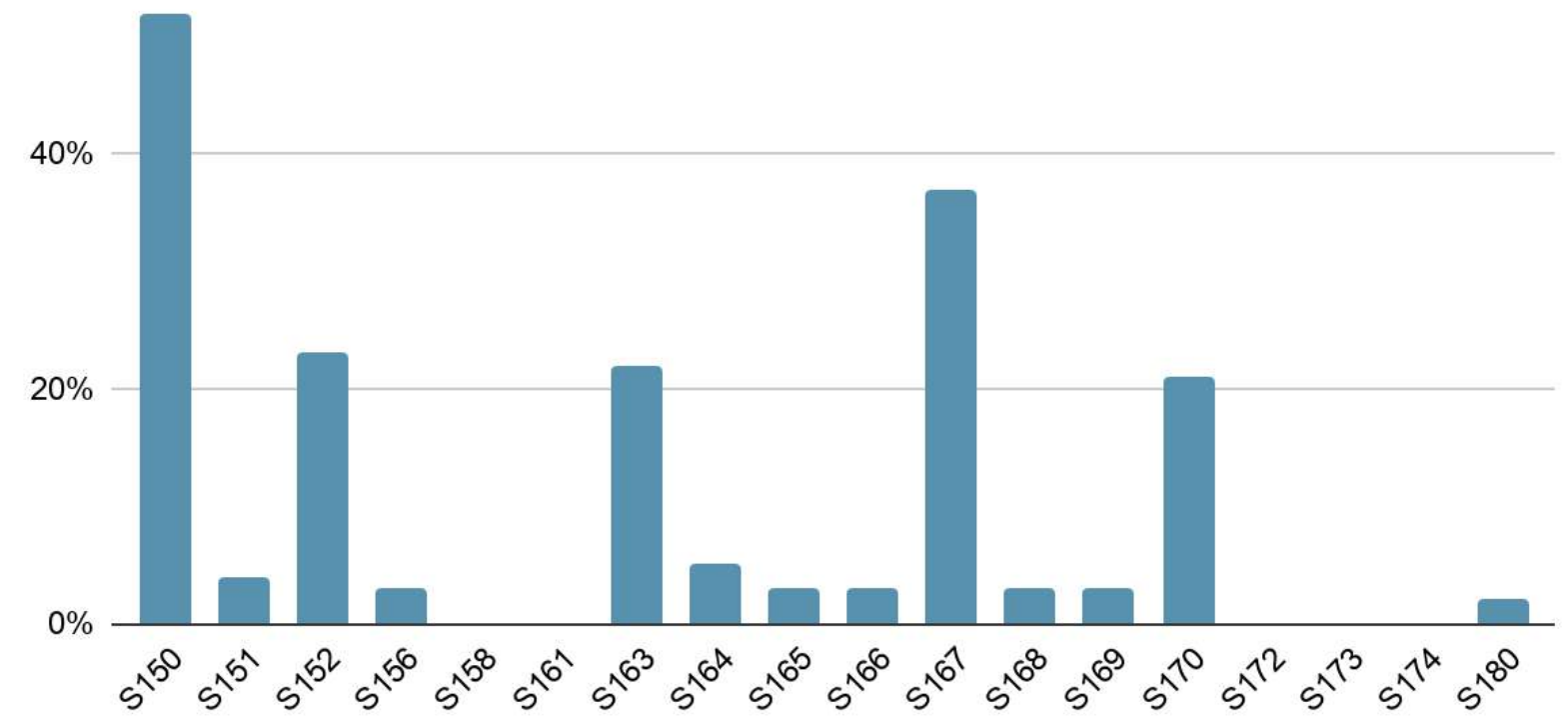

Figure 6 shows the percentage of change in use of $[\chi]$ by the participants in Spain. While most participants did not acquire this phoneme as much as $[\theta]$, all except five did improve in their use of this difficult phoneme during their time abroad. The mean percentage change was $10.1 \%$, and the median was only $3 \%$. The percentage of change in use is very different than that of $[\theta]$, since all but one participant did not use $[\chi]$ at any point during the pretest.

\section{Are social networks and years of previous instruction related to L2 dialectal acquisition?}

\section{Social Networks}

As previously mentioned, the social network data is used to analyze the acquisition of two peninsular phonemes: $[\theta]$ and $[\chi] .[\mathrm{s}]$ and $[\mathrm{h}]$ are used similarly in English and Spanish, whereas the peninsular phonemes $[\mathrm{x}],[\chi]$, and distinción do not exist in English. Because of this, 
the participants who went to Mexico are omitted from this section of analysis, though social network data was collected for the Mexico participants. The data from each abroad collection point was averaged to get a mean social network ( $\mathrm{SN})$ score. This analysis is primarily focused on the data from the mean SN score and the SN score from the third visit abroad. ${ }^{4}$

Table 5 below shows the mean SN score for the Spain participants and the percentage of change in their use of the phonemes $[\theta]$ and $[\chi]$ from the pretest to the third visit abroad.

\footnotetext{
${ }^{4}$ Though not analyzed in the present study, the Mexico participants had a mean of 3.85, a median of 3.67, and a standard deviation of 0.62. The Spain participants had a mean of 3.35, a median of 3, and a standard deviation 1.129. The participants who went to Mexico had slightly higher SN scores, likely due to living with host families, which many did compared to the Spain participants.
} 


\section{Table 5}

Percentage of change in use [ $\theta]$ and $[\chi]$ and mean SN score

\begin{tabular}{|c|c|c|c|}
\hline Participant & Mean SN Score & {$[\theta] \%$ change } & {$[\chi]^{\%} \%$ change } \\
\hline $\mathrm{S} 150$ & 4.33 & $48.04 \%$ & $51.67 \%$ \\
\hline $\mathrm{S} 151$ & 2.67 & $9.54 \%$ & $3.85 \%$ \\
\hline S152 & 4.67 & $4.54 \%$ & $23.08 \%$ \\
\hline S156 & 4.33 & $68.75 \%$ & $2.70 \%$ \\
\hline $\mathrm{S} 158$ & 3 & $0 \%$ & $0 \%$ \\
\hline S161 & 2.33 & $88.4 \%$ & $0 \%$ \\
\hline S163 & 3.67 & $7.79 \%$ & $21.74 \%$ \\
\hline S164 & 2.67 & $-9.05 \%$ & $5 \%$ \\
\hline S165 & 3 & $0.81 \%$ & $3.33 \%$ \\
\hline S166 & 5 & $2.37 \%$ & $3.45 \%$ \\
\hline S167 & 4.67 & $27.84 \%$ & $36.51 \%$ \\
\hline S168 & 2.67 & $71.30 \%$ & $3.33 \%$ \\
\hline S169 & 3.67 & $9.21 \%$ & $2.56 \%$ \\
\hline $\mathrm{S} 170$ & 2.67 & $11.11 \%$ & $21.43 \%$ \\
\hline S172 & 3 & $29.25 \%$ & $0 \%$ \\
\hline S173 & 5 & $-8.06 \%$ & $0 \%$ \\
\hline S174 & 2 & $-4.65 \%$ & $0 \%$ \\
\hline S180 & 1 & $69.34 \%$ & $2.27 \%$ \\
\hline
\end{tabular}




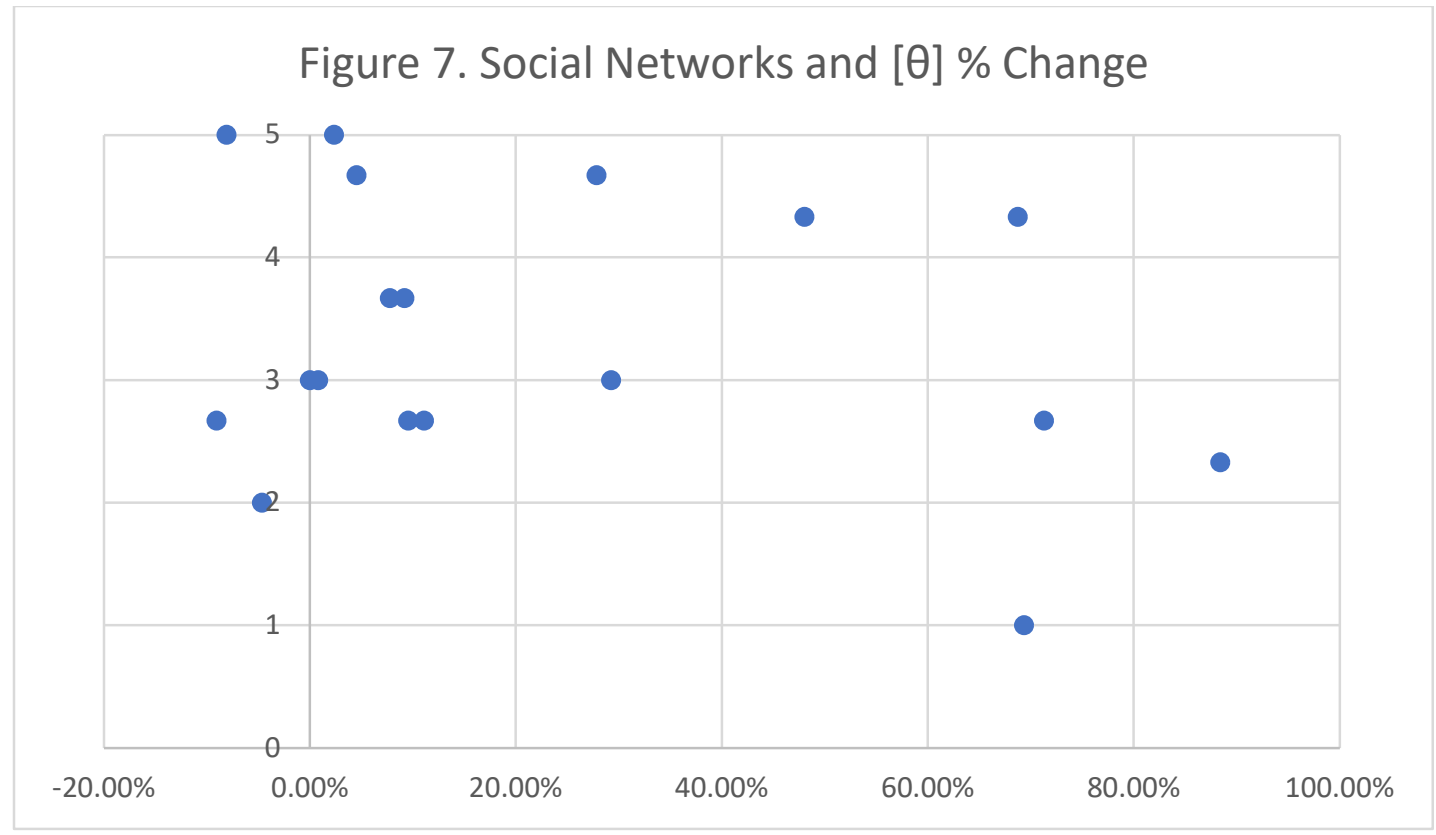

Figure 7 maps out the data from Table 5 as a correlation chart, with the $1-5$ being the SN value and the -20 to 100 representing the change in use of [ $\theta]$. The $r$-value equals -0.26 , which signifies a weak correlation. Contrasting previous research, this negative value suggests that the change in usage of $[\theta]$ decreases with stronger SNs, though the relsationship between the two factors is still very weak.

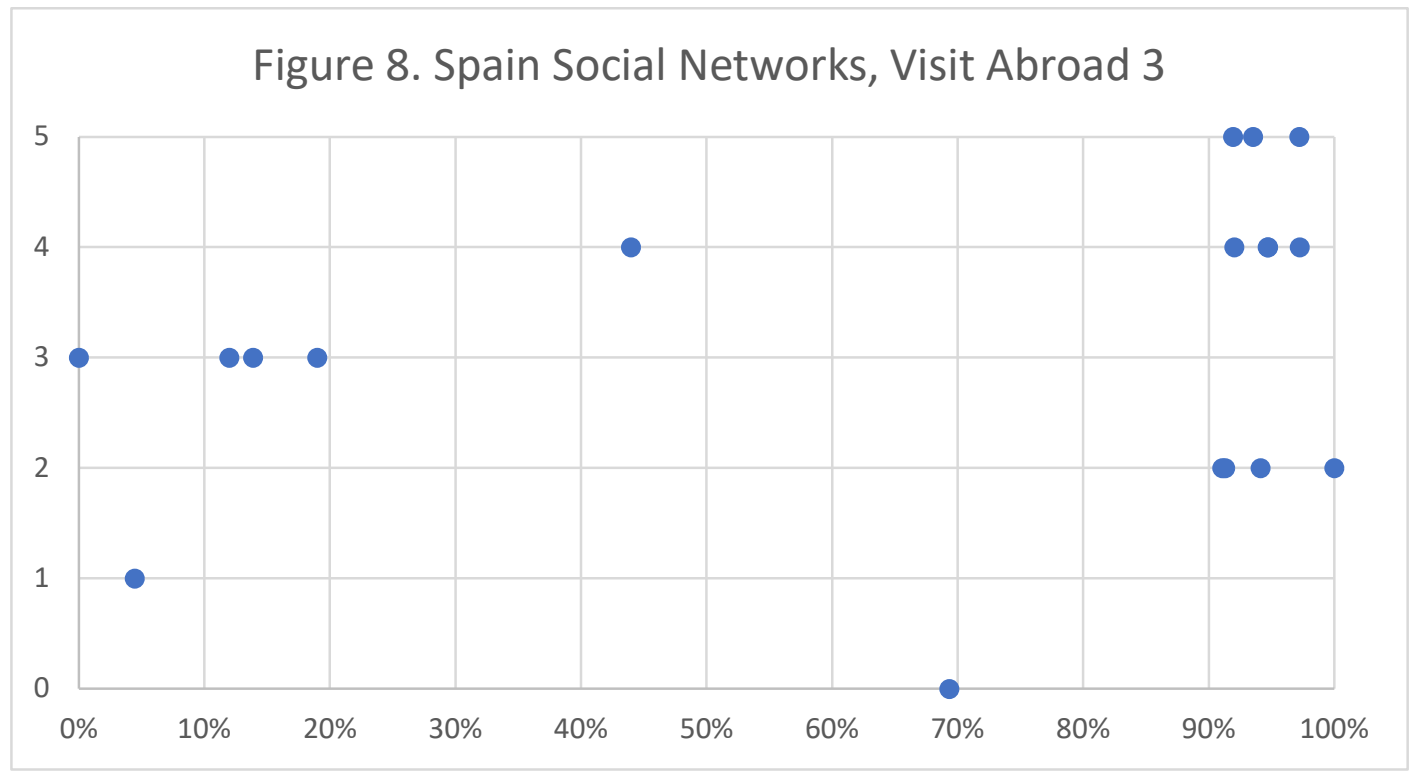


Figure 8 looks at the $\mathrm{SN}$ data from the third visit abroad as well as their use of [ $\theta]$ during that test. Because many participants were already using [ $\theta]$ during the pretest, looking at the SN data and the $[\theta]$ use at a specific point in time may offer other insights. For this data, the $r$-value equals 0.28 , again showing weak correlation, this time it is positive. There is a very slight relationship in the use of $[\theta]$ and having a strong $\mathrm{SN}$, though ultimately the correlation is weak.

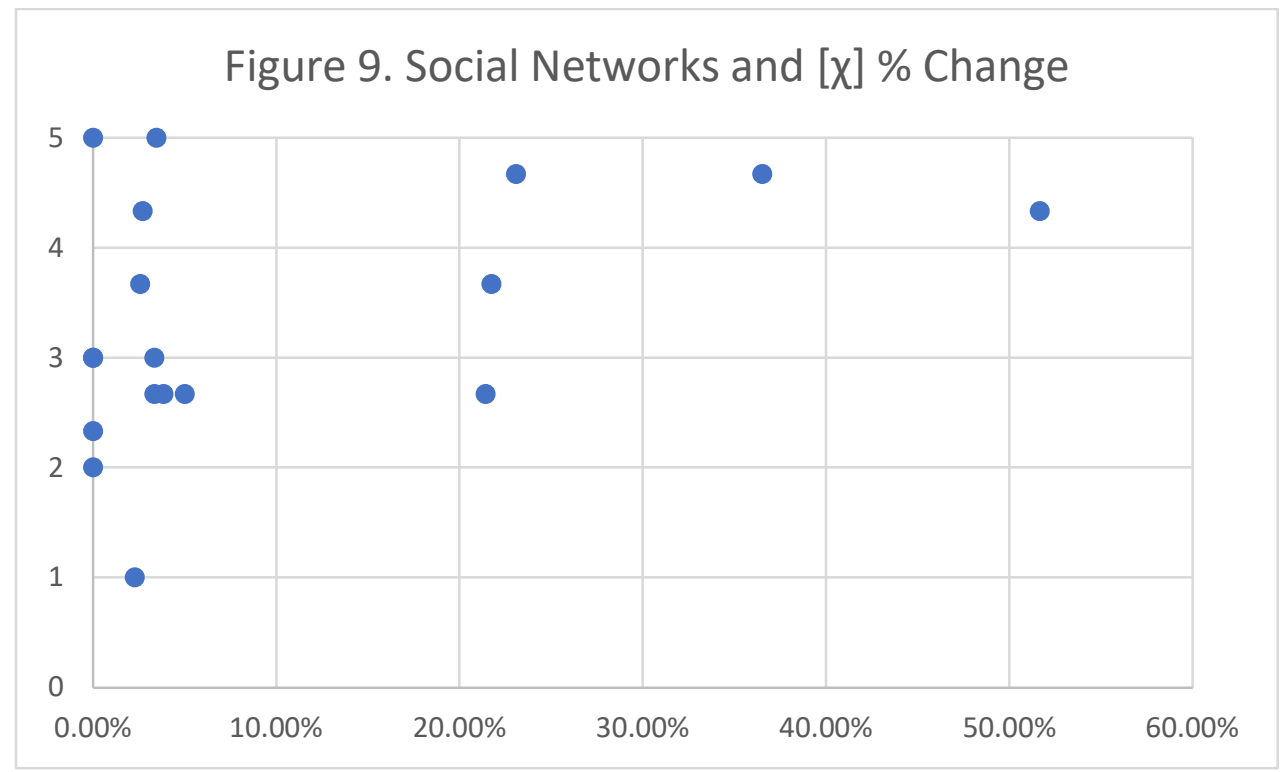

Figure 9 maps the SN values but compares those data with the increase in use of $[\chi]$. This results in a $r$-value of 0.4 , which shows a moderate correlation. This shows a slight positive correlation in the use of $[\chi]$ and having strong SNs, though more data would need to be collected and analyzed to further show a relationship between the two factors. 


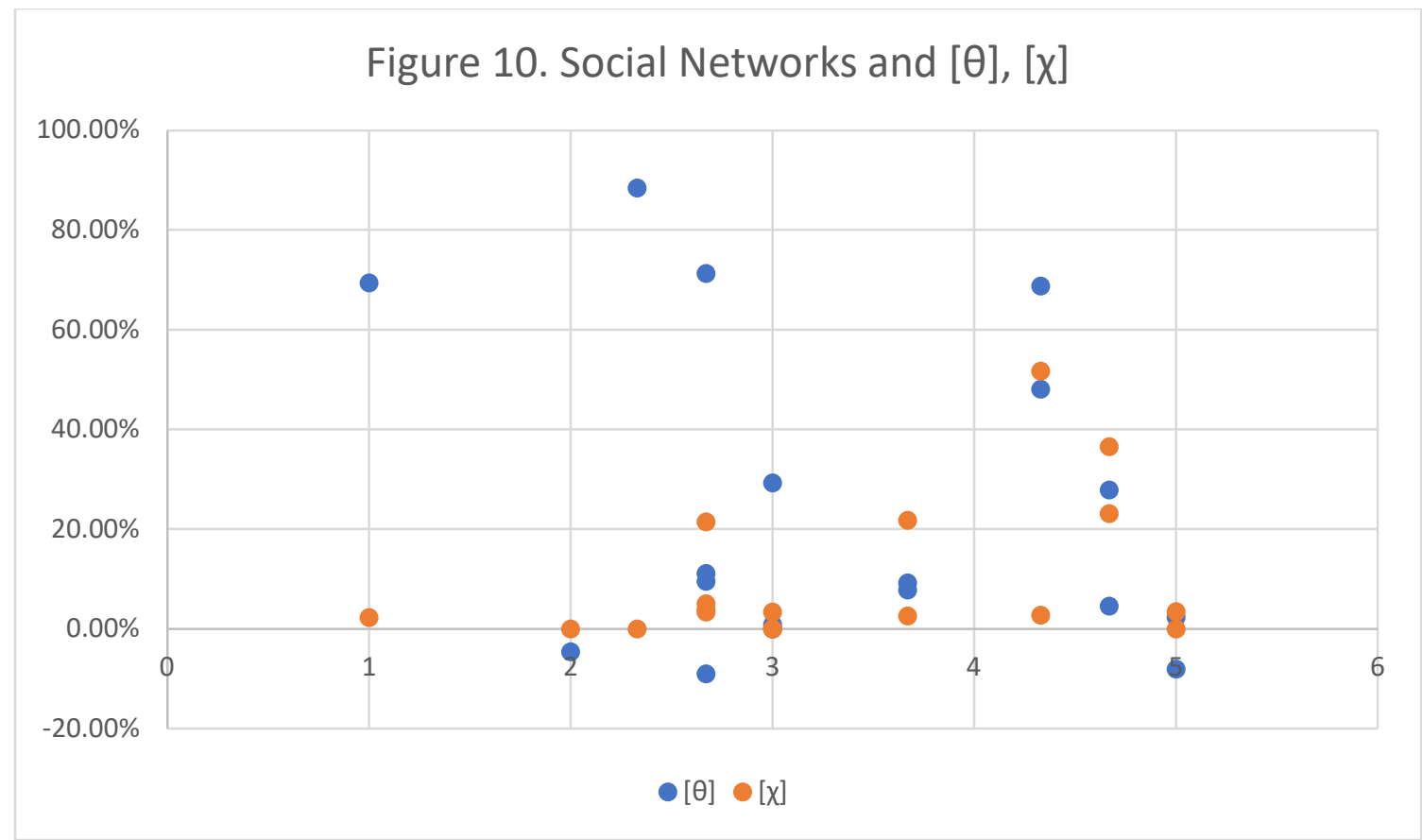

Figure 10 shows the $\mathrm{SN}$ data and its relationship to $[\theta]$ and $[\chi]$, in order to see if there was a pattern in which participants were acquiring both phonemes at similar rates. There did not seem to be any relationship between acquisition of these phonemes as they relate to SNs. There were higher rates of $[\theta]$ than $[\chi]$, however acquisition of one phoneme did not indicate acquisition of another phoneme.

\section{Years of Prior Instruction}

Data on years spent learning Spanish was collected as part of the study. This data was compared to the percentage of change in use of $[\theta]$ from the pretest to the posttest. The results are demonstrated in Figure 11 below. 


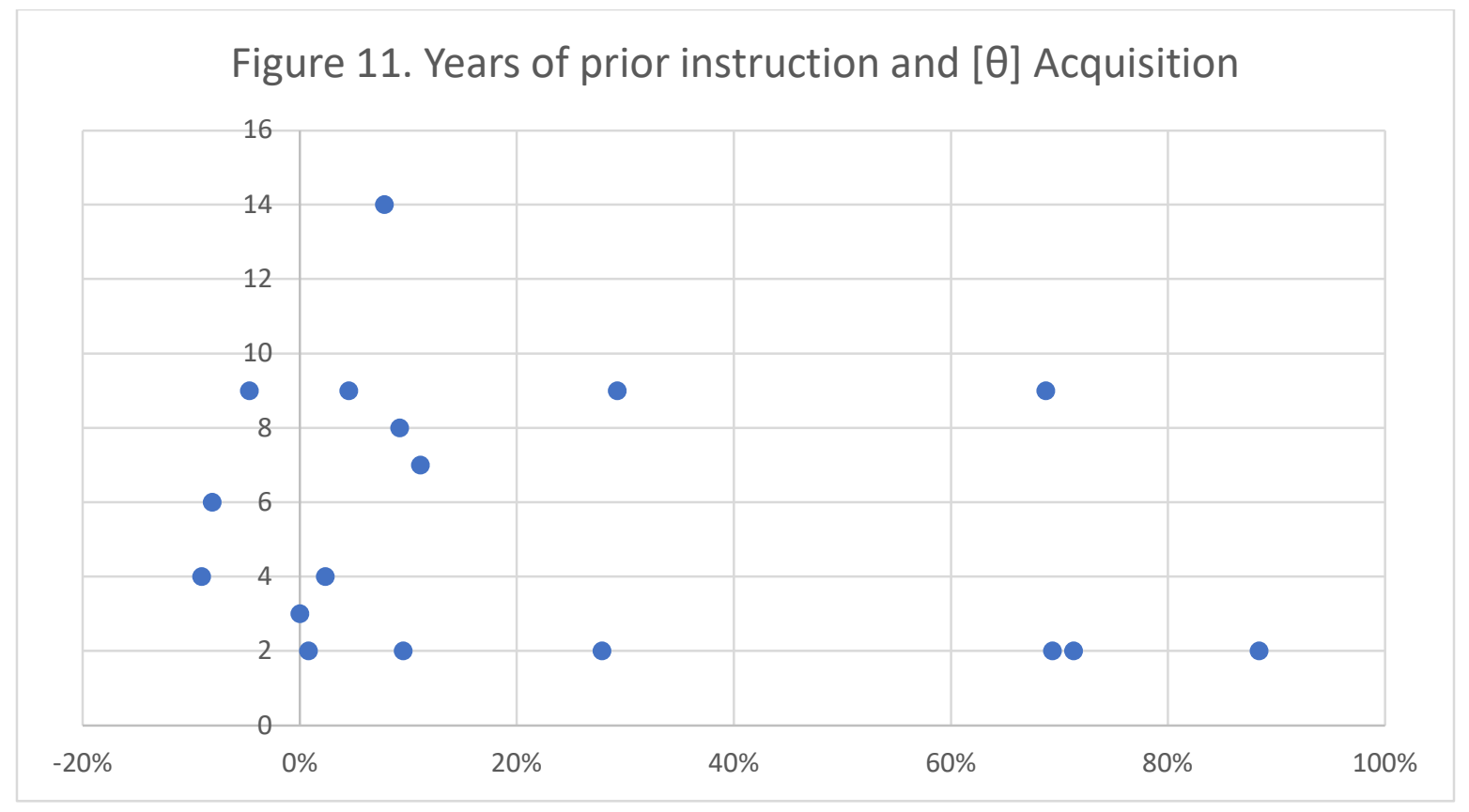

The correlation of years of prior instruction and acquisition of $[\theta]$ has a weak and negative correlation, $\mathrm{r}=-0.26$. This correlation, though weak, indicates that as students gain more years of instruction, they are less likely to change in use of dialectal features. Ultimately an insignificant relationship was found between these two factors, which is consistent with the results of Pozzi (2017) and Geeslin \& Gudmestad (2011). 


\section{Discussion}

Previous studies on L2 dialectal acquisition have found little, if any acquisition of variational features by L2 learners as a result of SA (Geeslin \& Gudmestad, 2008; Knouse, 2012; Pozzi, 2017; Ringer-Hilfinger, 2012; Schoonmaker-Gates, 2017). The results of the present study have shown that L2 learners are capable of acquiring such variational features of the region in which they studied, and at much higher rates than the previously mentioned studies. The results of this study agree with prior research (Geeslin, 2013; Mitchell et al., 2017; Regan et al., 2009; Ringer-Hilfinger, 2012) that SNs and NS contact are important to L2 dialectal acquisition, though the relationships were shown to be weakly correlated.

\section{Overall use of $[\mathrm{s}]$ and $[\theta]$}

A similar case of acquisition with the Mexico participants occurs with the alveolar fricative. There were only two participants in this group who did not use [ $\theta]$ at any point during the pretest, and as expected, it was never acquired during their time abroad. Seven participants used it during the pretest, but they all regressed significantly after their year abroad. Participant 155 used $[\theta]$ in $1 \%$ of contexts $(n=1)$, but this is still $86 \%$ less than what was used in the pretest. Participant 177 used the interdental fricative in 94\% of contexts during the pretest and showed complete acquisition of [s] during the posttest. While their high rates of [s] usage is certainly expected as a result of a year abroad immersed in a seseo dialect, no other study has looked at this. Studies on [ $\theta$ ] acquisition such as Geeslin \& Gudmestad (2008), Knouse (2012), Schoonmaker-Gates (2017), and Ringer-Hilfinger (2012) focus on participants who primarily have learned seseo dialect, and their findings show little and unpredictable use of [ $\theta]$. All of these studies suggest that prior exposure and instruction may lead to increased use of the interdental fricative, which the present study seems to affirm with the high levels of [ $\theta]$ usage in 
the pretest and posttest. This study also suggests that seseo dialectal acquisition is possible by participants who have learned dialects with distinción.

Measuring acquisition of $[\theta]$ was difficult in the Spain participant because many participants were already using $[\theta]$ in the majority of possible contexts, so it is unclear if they increased in usage of this feature after their SA experience. As previously mentioned, this suggests that many of the participants had learned dialects with distinction, either in the classroom or through short-term abroad experiences to Spain, where this variant is used.

Still, the data suggests that many participants who went to Spain did increase in their use of this regional feature. Except for participant 158, all participants $(n=17)$ used the interdental fricative in the posttest. Participant 180 was the only participant who did not use [ $\theta]$ at any point during the pretest and used it during the posttest, in $69 \%$ of contexts. Other large changes were made by participants $150,156,161$, and 168 , who increased in their use of the regional feature by $48 \%, 69 \%, 88 \%$, and $71 \%$ respectively.

Looking at the percentage of change in use of $[\theta]$, there was some evidence of a decrease in the use of the regional feature during the year abroad. Three participants $(164,173,174)$ used the interdental fricative less in the posttest. While this is true, it does not necessarily mean a regression in the use of the regional phoneme. For example, participant 174 used [ $\theta]$ in $92 \%$ of contexts during the posttest, which is down from $100 \%$ of contexts in the pretest. It is most likely that this is just a result of variation in an individual's speech and not an actual decrease in the use of dialectal phonemes. The same can be said for participants 164 and 173, even though they do not show as strong use of the regional phoneme, there is little change in usage. 
In a small pilot study on gender, identity, and SNs, Lindley (2020) found that internal linguistic factors were not related to predicted use of $[\theta]$. In this study, looking at different contexts where $[\theta]$ or $[\mathrm{s}]$ may be produced, no context was shown to be more likely for [s] or $[\theta]$ to be produced (for example, before a vowel, before a consonant, word-final, etc.). Of these different contexts, participants were slightly more likely to produce [ $\theta$ ] for proper nouns related to Spain (Andalusia, Valencia, Barcelona, etc.) and [s] for cognates (decidir to decide, ciencias science, etc.). This was not the main focus of the present study, but still noteworthy to mention that certain contexts were not reliable predictors of which phoneme would be produced.

Variation of $[\theta]$ exists within mainland Spain, with certain areas of Andalusia using ceceo or seseo, which varies greatly depending on the area and individual speaker. The majority of participants were in regions where distinción is most prevalent, though few were in regions where сесео and seseo may be employed. This did not seem to affect participants' use of [ $\theta]$.

As previously mentioned, there was one participant who did not acquire $[\theta]$ at any point during the study. Participant 158 was the only Spain participant who did not use the regional phoneme during the pretest and posttest. According to previous research, it is uncommon for data to show large amounts of dialectal acquisition, so it should be expected that there would be participants who did not change in this aspect. That being said, there was only one participant who this applied to, so it is worth being noted. Participant 158 was one of two L1 Polish speakers, so it is plausible that this could have affected the L2 regional acquisition. Qualitative evidence suggests, though, that it may have been a result of a lack of strong connection to the host country: "Me he dado cuenta que España no es un país para vivir para mi"” (I have realized that Spain is not a country for me to live). Many participants recognized their stay as temporary, but 158 was the only participant who expressed feelings of not wanting to return. 
While this is not a definitive reason as to why this participant did not use [ $\theta$ ] after their SA, it is consistent with the results of Ringer-Hilfinger (2012), who suggested that positive L2 experiences and attitudes may be related to higher use of dialectal phonemes. Another reason for the results of participant 158 is they notably did not have an overall positive experience, therefore there would be no motivation to use those dialectal features. This is consistent with the research on L2 motivation (Baumeister, 1986; Block, 2007; Dörnyei \& Ushioda, 2009; McManus et al., 2014; Rubenfeld et al., 2006), which suggests that positive SNs with the target language and culture influences L2 identity and acquisition.

\section{Overall use of $[h],[x]$, and $[\chi]$}

As anticipated, participants varied in their use of $[\mathrm{h}],[\mathrm{x}]$, and $[\chi]$ both before and after the year abroad. In the pretest, the majority of participants $(n=24)$ did not use the uvular fricative at all, and nine participants exclusively used the glottal fricative. In the posttest, all 27 participants used a mix of $[\mathrm{h}]$ and $[\mathrm{x}]$. Because the uvular fricative is not present in Mexico, it is expected that there would not be any use from those participants.

From the participants who went to Spain, 13 participants produced $[\chi]$ in the posttest, only one of them having produced it in the pretest. Though there were five participants who went to Spain who did not produce $[\chi]$ at all, they all acquired the velar fricative during their time abroad. Every participant who went to Spain showed more instances of the sounds typically used in this variety, though several participants actually decreased in their use of $[\mathrm{x}]$ in favor of $[\chi]$.

In Mexico, both the velar and glottal fricative are used, depending on the region. In the participants who went to Mexico, many $(\mathrm{n}=8)$ were using a mix of $[\mathrm{h}]$ and $[\mathrm{x}]$ during the pretest, with two participants (175 and 177) using $[\chi]$. The participant with the largest increase, 179, used [h] in $100 \%$ of contexts during the pretest, and produced $[\mathrm{x}] 25 \%$ of the time in the posttest. All 
other participants preferred the glottal fricative, which is less present in dialects of Mexico. Since the glottal fricative is common in Caribbean dialects, and certain regions of Mexico have more Caribbean influences, this may be why participants favored [h] (Hualde et al., 2012). Since velar and glottal fricatives are similar, it is also possible that participants preferred the feature that was already present in their L1. The effects of the peninsular dialect on the participants who went to Mexico are extremely evident, as every participant (except 179), improved in their use of [h] during their time abroad and decreased in their use of [x]. Participant 175 is especially noteworthy here, as they used $[\chi]$ in $10 \%$ of contexts during the pretest, and $0 \%$ during the posttest.

The majority of prior research (Geeslin \& Gudmestad, 2008; Knouse, 2012; RingerHilfinger, 2012; Schoonmaker-Gates, 2017) on L2 dialectal acquisition focus on [ $\theta$ ], the present study suggests that the same conclusions can be drawn with other dialectal features, such as the allophones of [x]. Pozzi (2017) made similar conclusions with L2 use of dialectal phonemes of Buenos Aires, Argentina, showing that the factors affecting dialectal acquisition are not specific to the voiceless interdental fricative.

\section{Social Networks}

Though participant 158 did not express positive feelings about their experience, they developed a decent social network during their time abroad (average $\mathrm{SN}=3$ ). Prior research (Diaz-Campos, 2004; Geeslin \& Gudmestad, 2008; Mitchell et al., 2017; Regan et al., 2009; Ringer-Hilfinger, 2012; Shively, 2008) suggests that stronger SNs are related to higher levels of L2 dialectal acquisition, but this was not the case with participant 158.

This was also not the case with most participants. There did not seem to be any relationship between $\mathrm{SNs}$ and acquisition of $[\theta]$ or $[\chi]$. The mean $\mathrm{SN}$ for the Spain participants 
was 3.35; with 8 participants having a SN score above this mean. Of these eight participants, only three had a percentage change in use of $[\theta]$ above the mean of $23.7 \%$. Thus, out of 18 Spain participants, only three had a positive relationship between their $\mathrm{SN}$ and use of [ $\theta]$. This is contrastive to previous studies like that of Diaz-Campos (2004), which identify strong SNs as a factor that affects L2 dialectal acquisition. While the SN data of the Mexico participants were not looked at as rigorously, perhaps this explains the high levels of seseo acquisition, as the mean SN score of Mexico participants was slightly higher than that of the Spain participants.

Overall, the SN data was inconclusive. As unexpected as it was, it is not without explanation. The SN questionnaire had five areas, in which participants received one "point" for each area that they were participating in. Of the five areas analyzed, only one of them analyzed exclusive L2 use, with the other four looking at L2 and mixed interactions. Because the SN questionnaire analyzed L2 use in many mixed contexts, the data is not that accurate to analyze participants' SNs with the regional variety. The raw data on these mixed contexts was not available for the present study, so conclusions about whether these interactions were beneficial cannot be made. The data would be more conclusive if it showed whether the contexts were with NSs of the specific regional varieties. Thus, the SN questionnaire does not analyze SNs in a way that would be necessary in order to make certain conclusions about the relationship between SNs and L2 dialectal acquisition. This data would have been more beneficial if it was geared towards L2 use with NSs, or speakers of that specific regional dialect, as L2 use alone was not related to L2 dialectal acquisition. For this type of study, a SN questionnaire that measured the quality of L2 use would have been more beneficial than one that measured the quantity of L2 use.

This does not mean that the SN questionnaire is not beneficial to the study. Along with previous research (Diaz-Campos, 2004; McManus et al., 2014; Pozzi, 2017; Regan et al., 2009; 
Ringer-Hilfinger, 2012), it suggests that the quality of SNs made during SA experiences may be related to L2 dialectal acquisition. There was a weak relationship found between L2/mixed use and L2 dialectal acquisition. It is possible that there may be a relationship to SNs with NSs of the specific dialect and L2 dialectal acquisition, which is further discussed in the next section of this study. 


\section{Limitations and Further Research}

One of the most notable limitations of the present study is the lack of analysis on participants' awareness and perceptions of $[\theta]$ and $[\chi]$. While L2 dialectal acquisition occurred for many participants, some participants, most notably participant 158 , did not seem to acquire any regional phoneme. Qualitative data was used to explain the lack of acquisition of this participant, however, data explicitly about regional variation is beneficial for this kind of study. Many participants improved in their dialectal acquisition, and a questionnaire on participants' perceptions and awareness could supplement this data (such as those from Ringer-Hilfinger, 2012 and Knouse, 2012). Like previous studies, this study was unable to pinpoint exact factors that are related to (non) acquisition of dialects, and a questionnaire on attitudes, perceptions, and awareness of variations may have been helpful in order to determine certain factors, though it was inaccessible for the type of study.

Of the three activities that were used in the data collection points of the LANGSNAP project, this study only analyzed the semi-structured interview. The writing activity was omitted for obvious reasons, and the narrative activity was not substantial enough to provide any useful insight to the study. The semi-structured interview was extremely beneficial as participants were able to speak naturally, so the data elicited most likely reflects their actual speaking habits. The questions used in the interview were also beneficial to provide certain qualitative data when necessary. While this activity elicited enough data on its own, different types of tasks could be used in future studies in order to elicit different types of speech. For example, a word list or a read-aloud activity with strategic words (ones that contain $[\theta]$ and $[\chi]$ ) may show a different type of use of those regional phonemes. While natural speech is best to determine acquisition, word lists and read-aloud activities can provide evidence as to whether participants are trying to 
incorporate certain phonemes into their speech. This was beyond the scope of the present study, though it could be used for future analyses. Future researchers could also look at the acoustic analysis of the data in Praat, as the present study relied on perceptual analysis, due to the large number of tokens.

Though the present study was the most longitudinal of its kind, there remain points for further research. In the LANGSNAP project, there were six points of data collection, though the present study focused on only two of those collection points. The data points selected were the most informative to L2 dialectal acquisition during SA, however further research could be done that includes the other data as well. Most notably, the two visit abroad collection points that were omitted from this study could be used to analyze the progression of acquisition of regional phonemes, in order to gain insight into the necessary time frame needed to acquire dialects during SA. The data from the first two visit abroad points could be especially noteworthy to see how rapidly the participants who went to Mexico stopped using [ $\theta]$ during their time abroad. This study suggested that one year is sufficient for increase of L2 dialectal phonemes, as previous studies are not as longitudinal and many studies show little to no dialectal acquisition. The two tests that were done after the SA could also be analyzed to study the retention of regional phonemes that participants acquired during their time abroad, for both groups. Though many participants showed increased use, further research could be done to see what that acquisition looked like after being removed from the SA context, specifically to see if identifying with their experience was significant to continue using those features. Again, for this study, the other points were beyond the scope, but could be analyzed in further studies.

Because the reasons why L2 learners acquire dialectal features seem to be personal, a case-study approach using qualitative data may be useful for further research on the subject. 
Because acquisition of these phonemes is optional, focusing on one or two participants and their reasons for increased use of these phonemes would be beneficial, as the present study did not contain data on participants' opinions of L2 dialects. This would be beneficial for participants who went to Spain or Mexico, as both groups seemed to use features that were present in the region where they studied, though it would be interesting to compare two differing varieties within Spain.

\section{Teaching Implications}

The way that the present study most notably differs from previous studies is the participants' use of [ $\theta$ ] prior to the SA. As mentioned, this is likely because the participants are from England, where many of their primary teachers and university professors may utilize $[\theta]$ in their speech. This is vastly different from the situation in the United States, where most teachers and professor use neutralized Latin American dialects in the L2 classroom. This may ultimately influence L2 Spanish students' own dialects, as they will mimic the input that they receive. This study suggests that using different dialects in the classroom can be beneficial to students as they interact with NSs of the target language outside the classroom.

Because many researchers affirm that SA benefits oral fluency and cultural acquisition (Mcmanus et al., 2020; Mitchell et al., 2017; Segalowitz \& Freed, 2004), the assumption can be made that many L2 Spanish learners (such as those who are majoring in Spanish or a related field) will go abroad at some point. If L2 Spanish learners are going abroad, L2 instructors must be diligent at preparing them for interactions with NSs of many regions. This includes exposure and instruction on certain dialects so that L2 learners can comprehend and acquire phonological 
variations during their time abroad, which may ultimately enhance their SA experience and overall L2 self-image.

\section{Conclusion}

Compared to previous studies on the subject (Geeslin \& Gudmestad, 2008; Knouse, 2012; Ringer-Hilfinger, 2012), the participants in the present study vastly improved in their use of regional phonemes during their sojourn, perhaps due to their high levels of use in the pretest, showing that exposure and instruction can be beneficial to L2 dialectal acquisition. The mean percentage of change in $[\theta]$ usage for Spain participants was $23.7 \%$, with half $(n=9)$ improving in their use above the median $9.5 \%$. While participants did not increase in their use of $[\chi]$ as much as they did $[\theta]$, though many participants still acquired the phoneme in some way $(n=13)$. The mean use of $[\chi]$ in the posttest was $10.7 \%$, and the median only being $3 \%$. While most participants did increase in use both phonemes, [ $\theta]$ was favored over the glottal fricative. Regional phonemes were notably produced in Mexico, as every single participant did not use [ $\theta]$ at the end of their sojourn. Even though most participants $(n=7)$ used it prior to the sojourn, only one participant (177) used it once during the posttest.

While previous studies (Geeslin \& Gudmestad, 2008; Pozzi, 2017; Ringer-Hilfinger, 2012) suggest that SNs are related to L2 dialectal acquisition, the data from this study suggested there was a weak relationship between the two. While participants in both Spain and Mexico generally developed strong SNs (mean=3.52) during their time abroad, their SN strength was, on average, not correlated with use of regional phonemes. As mentioned, this was likely due to their SNs being reflective of their overall L2 use, rather than their L2 use with native speakers of that 
region. It is possible that the participants were frequently using the target language with other speakers while having little contact with regional phonemes such as $[\theta]$ or $[\chi]$.

Another possible reason to explain the differences in acquisition is their L2 identity. Instead of identifying with the L2 language or culture, many of the participants viewed themselves as a "temporary sojourner" (Mcmanus et al., 2020). This may have played a role in the lack of acquisition of certain participants, though more research would need to be done in order to substantiate that claim. 


\section{References}

Amoros-Negre, C. (2016). The spread of Castilian/Spanish in Spain and the Americas: A relatively successful language standardisation experience. Sociolinguistica, 30 . https://doi.org/10.1515/soci-2016-0003

Barron, A. (2005). Variational pragmatics in the foreign language classroom. System, 33(3), 519-536. https://doi.org/10.1016/j.system.2005.06.009

Baumeister, R. F. (Ed.). (1986). Public Self and Private Self. Springer-Verlag. https://doi.org/10.1007/978-1-4613-9564-5

Block, D. (2007). Second Language Identities. Journal of Language, Identity \& Education, 9(3), 225-228. https://doi.org/10.1080/15348458.2010.486279

Diaz-Campos, M. (2004). Context of learning in the acquisition of Spanish second language phonology. Studies in Second Language Acquisition, 26(2), 249-273.

Diaz-Campos, M. (2011). The Handbook of Hispanic Sociolinguistics. John Wiley \& Sons, Incorporated. http://ebookcentral.proquest.com/lib/wvu/detail.action?docID $=661774$

Dörnyei, Z., \& Ushioda, Dr. E. (2009). Motivation, Language Identity and the L2 Self. Channel View Publications. http://ebookcentral.proquest.com/lib/wvu/detail.action?docID=408815

Eckert, P. (1988). Adolescent Social Structure and the Spread of Linguistic Change. Language in Society, 17(2), 183-207.

Freed, B. F., Dewey, D. P., Segalowitz, N., \& Halter, R. (2004). The Language Contact Profile. Studies in Second Language Acquisition, 26(2), 349-356. 
Freed, B. F., \& Ferguson, C. A. (1995). Second Language Acquisition in a Study Abroad Context. John Benjamins Publishing Company. http://ebookcentral.proquest.com/lib/wvu/detail.action?docID=784235

Geeslin, K. L. (2013). The Handbook of Spanish Second Language Acquisition. John Wiley \& Sons, Incorporated. http://ebookcentral.proquest.com/lib/wvu/detail.action?docID=1418362

Geeslin, K. L., \& Gudmestad, A. (2010). An exploration of the range and frequency of occurrence of forms in potentially variable structures in second-language Spanish. Studies in Second Language Acquisition, 32(3), 433-463. https://doi.org/10.1017/S0272263110000033

Geeslin, K. L., \& Gudmestad, A. (2008). The acquisition of variation in second-language Spanish: An agenda for integrating studies of the L2 sound system. Journal of Applied Linguistics, 5(2), 137-157. https://doi.org/10.1558/japl.v5i2.137

George, A. (2014). Study Abroad in Central Spain: The Development of Regional Phonological Features. Foreign Language Annals, 47(1), 97-114. https://doi.org/10.1111/flan.12065

Gilakjani, A., Ahmadi, S., \& Ahmadi, M. (2011). Why is Pronunciation So Difficult to Learn? English Language Teaching, 4(3), p74. https://doi.org/10.5539/elt.v4n3p74

Hualde, J. I., O’Rourke, E., \& O'Rourke, E. (2012). The Handbook of Hispanic Linguistics (A. Olarrea, Ed.). John Wiley \& Sons, Incorporated. http://ebookcentral.proquest.com/lib/wvu/detail.action?docID=861859

Knouse, S. M. (2012). The acquisition of dialectal phonemes in a Study Abroad Context: The Case of the Castilian Theta. Foreign Language Annals, 45(4), 512-542.

Lipski, J. M. (2008). Varieties of Spanish in the United States. Georgetown University Press. 
McManus, K., Mitchell, R., \& Tracy-Ventura, N. (2014). Understanding insertion and integration in a study abroad context: The case of English-speaking sojourners in France. Revue francaise de linguistique appliquee, Vol. XIX(2), 97-116.

Mcmanus, K., Mitchell, R., \& Tracy-Ventura, N. (2020). A Longitudinal Study of Advanced Learners' Linguistic Development Before, During, and After Study Abroad. 29.

Miller, K., \& Schmitt, C. (2010). Effects of variable input in the acquisition of plural in two dialects of Spanish. Lingua, 120(5), 1178-1193. https://doi.org/10.1016/j.lingua.2008.05.009

Mitchell, R., Tracy-Ventura, N., \& McManus, K. (2017). Anglophone Students Abroad: Identity, Social Relationships, and Language Learning. Taylor \& Francis Group. http://ebookcentral.proquest.com/lib/wvu/detail.action?docID=4831545

Muñoz, C., \& Llanes, À. (2014). Study abroad and changes in degree of foreign accent in Children and Adults. Modern Language Journal, 98(1), 432-449.

Munro, M. J., \& Derwing, T. M. (1999). Foreign Accent, Comprehensibility, and Intelligibility in the Speech of Second Language Learners. Language Learning, 49(s1), 285-310. https://doi.org/10.1111/0023-8333.49.s1.8

Munson, B., Edwards, J., \& Beckman, M. E. (2011). Phonological Representationsin Language Acquisition: Climbing The Ladder of Abstraction. Oxford University Press. https://doi.org/10.1093/oxfordhb/9780199575039.013.0012

Nycz, J. (2013). Changing words or changing rules? Second dialect acquisition and phonological representation. Journal of Pragmatics, 52, 49-62. https://doi.org/10.1016/j.pragma.2012.12.014 
Pozzi, R. (2017). The acquisition of regional features during a semester abroad in Buenos Aires, Argentina [Doctoral Dissertation]. ProQuest.

Regan, Prof. V., Howard, M., \& Lemée, Dr. I. (2009). The Acquisition of Sociolinguistic Competence in a Study Abroad Context. Channel View Publications. http://ebookcentral.proquest.com/lib/wvu/detail.action?docID=449877

Ringer-Hilfinger, K. (2012). Learner Acquisition of Dialect Variation in a Study Abroad Context: The Case of the Spanish [0]. Foreign Language Annals, 45(3), 430-446. https://doi.org/10.1111/j.1944-9720.2012.01201.x

Rubenfeld, S., Clément, R., Lussier, D., Lebrun, M., \& Auger, R. (2006). Second Language Learning and Cultural Representations: Beyond Competence and Identity. Language Learning, 56(4), 609-631. https://doi.org/10.1111/j.1467-9922.2006.00390.x

Schoonmaker-Gates, E. (2012). Perception of foreign accent in Spanish by native and nonnative listeners: Investigating the role of VOT and speech rate [Ph.D., Indiana University]. In ProQuest Dissertations and Theses. http://search.proquest.com/docview/1037817264/abstract/C488A875477140D6PQ/1

Schoonmaker-Gates, E. (2017). Regional Variation in the Language Classroom and Beyond: Mapping Learners' Developing Dialectal Competence. Foreign Language Annals, 50(1), 177-194. https://doi.org/10.1111/flan.12243

Segalowitz, N., \& Freed, B. F. (2004). CONTEXT, CONTACT, AND COGNITION IN ORAL FLUENCY ACQUISITION: Learning Spanish in At Home and Study Abroad Contexts. Studies in Second Language Acquisition, 26(02). https://doi.org/10.1017/S0272263104262027 
Shively, R. (2008). L2 acquisition of $[\beta],[\delta]$, and $[\gamma]$ in Spanish: Impact of experience, linguistic environment and learner variables. Southwest Journal of Linguistics, 27(2), 79-114.

Taylor, F. (2014). Relational view of the self in SLA. In S. Mercer \& M. Williams (Eds.), Multiple perspectives on the self in SLA (pp. 92- 102). Bristol: Multilingual Matters. 


\section{Appendix A}

\section{Oral Interview Questions - Pretest}

1. ¿Por qué decidiste estudiar idiomas? ¿Recibiste alguna influencia de tus profesores (o profesoras), tu familia o tus amigos?

2. ¿Has estado en España o algún otro país de habla hispana antes? ¿Con qué fin viajaste allí? ¿Qué aprendiste durante tu estancia en X? ¿Crees que esa experiencia te preparó de algún modo para tu Año en el Extranjero?

3. ¿Qué actividad vas a estar haciendo allá? ¿Por qué escogiste esta actividad/qué ventajas le ves a este esquema?

4. ¿Qué has hecho hasta ahora/has estado haciendo últimamente para preparar tu Año en el extranjero/el Año entrante?

5. ¿Tienes algún proyecto u objetivo personal que quieras lograr durante tu año en el extranjero? Ya sea lingüístico, cultural, personal, del vivir de manera independiente, etc?

6. ¿Cómo crees que pasarás el tiempo mientras estés en el extranjero? ¿Estarás trabajando? ¿En qué consisitirá tu trabajo? ¿Y cómo piensas pasar tu tiempo libre y/o hacer tiempo para hacer tu proyecto y estudiar?

7. ¿Cómo piensas hacer amigos allá? ¿Cómo planeas conocer gente y qué tipo de personas te gustaría conocer?

8. ¿Qué ideas tienes/ qué piensas hacer para escuchar y practicar el castellano mientras estés allá? Ya sea en la universidad, el trabajo, en casa o en tu tiempo libre.

9. ¿Cómo esperas que sea este año? ¿De qué manera crees que será diferente a tu vida en Home University? ¿Qué retos crees que te traiga esta experiencia?

10. ¿Crees que el ser hombre/mujer te traerá alguna ventaja o desventaja? ¿Crees que sería distinto si fueras hombre/mujer?

\section{Oral interview questions - Visit Abroad 3}

1. Cuéntame ¿qué ha pasado desde mi última visita/la última visita que te hice? ¿Sigues viviendo en el mismo lugar, con las mismas personas? ¿Qué tal va todo en el trabajo/con la universidad?

2. Describe un día típico para ti.

3. ¿Qué haces en tu tiempo libre?

4. ¿Con quién pasas la mayor parte de tu tiempo?

5. Cuéntame algo memorable que te haya pasado últimamente.

6. ¿Qué problemas/dificultades/retos/sorpresas se te han presentado recientemente? ¿Has tenido alguna dificultad con la lengua?

7. ¿Crees que tu español haya mejorado desde la última visita? ¿En qué aspectos?

8. ¿Qué actividades tienes planeadas para tus últimos días aquí? (si ya no tienes nada planeado ¿qué te gustaría hacer? ¿Cómo los querrías pasar?)

9. ¿Qué es lo que más echarás de menos (extrañarás) de tu vida aquí al volver a Inglaterra?

10. Puedes darme un ejemplo (o dos) de algo que hayas aprendido durante tu estancia en Spain/Mexico, que te hubiera gustado saber antes de venir aquí? Algo útil que sea de ayuda para los estudiantes que vayan a venir aquí el próximo año. 